Available online at http://docs.lib.purdue.edu/jate

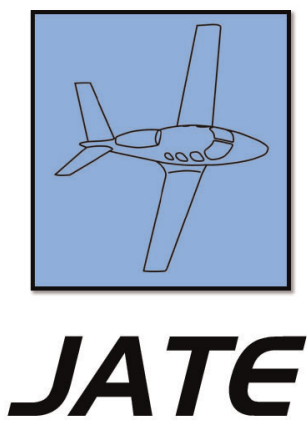

Journal of Aviation Technology and Engineering 6:2 (2017) 50-79

\title{
Pilot Source Study 2015: A Comparison of Performance at Part 121 Regional Airlines Between Pilots Hired Before the U.S. Congress Passed Public Law 111-216 and Pilots Hired After the Law's Effective Date
}

\author{
MaryJo O. Smith \\ (Ypsilon Associates) \\ Guy M. Smith \\ (Embry-Riddle Aeronautical University-Daytona Beach) \\ Elizabeth Bjerke \\ (University of North Dakota) \\ Cody Christensen \\ (South Dakota State University) \\ Thomas Q. Carney \\ (Purdue University) \\ Paul A. Craig \\ (Middle Tennessee State University) \\ Mary Niemczyk \\ (Arizona State University)
}

\section{Abstract}

This article is the third in a series of reports called Pilot Source Study 2015. In 2010, when the U.S. Congress considered dramatic changes to airline pilot qualifications, researchers from the "Pilot Source Study 2010" sampled pilots from six regional airlines to investigate how pilots' backgrounds affected their performance in airline training. In 2012, when the FAA proposed rulemaking to 
implement Public Law 111-216, the "Pilot Source Study 2012" researchers repeated the study with a new sample of pilots from seven different regional airlines. Data from these two studies were combined into a Pre-Law dataset. On August 1, 2013, the mandates of PL 111-216 became effective, ushering in the Post-Law era. The Pilot Source Study 2015 consists of three articles that cover the 19 U.S. regional airlines operating under 14 CFR Part 121. This report (Article 3) compares pilots' training outcomes between Pre-Law and PostLaw to determine whether their backgrounds had a stronger or weaker influence on Post-Law outcomes. Background variables were segmented into: (a) educational backgrounds, which occur early when pilots obtain their certificates and (b) experience backgrounds, which occur later when pilots accumulate flight time before applying to a regional airline. When comparing the Pre-Law and Post-Law data, educational backgrounds generally had less effect on airline training outcomes. Experience backgrounds also generally had less effect on airline training outcomes, with these exceptions: (a) previous airline and corporate experience had a more positive effect on extra training events, and (b) previous corporate experience had a more positive effect on completions. In conclusion, the congressionally mandated gap between earning pilot certificates and beginning airline training has reduced the positive effects of pilots' educational and experience backgrounds.

Keywords: Pilot Source Study, Public Law 111-216, Pilot Certification and Qualification Requirements for Air Carrier Operations, FOQ Rule, 14 CFR Part 121, ATP, R-ATP, pilot hiring, pilot training, first officer, transportation law, Airline Safety and Federal Aviation Administration Extension Act, airline pilot, new-hire pilot, flight hours, AABI, operating experience, recurrent training

\section{Introduction}

In the aftermath of the 2009 crash of Colgan Air Flight 3407 (National Transportation Safety Board [NTSB], 2010), Congress unanimously passed the Airline Safety and Federal Aviation Administration Extension Act of 2010. That law, also known as Public Law 111-216, went into full effect on August 1, 2013. The new law suspended career opportunities for many low-time pilots and has made it challenging for airlines to find qualified pilot applicants (McGee, 2015). Previously, air carriers certificated under 14 CFR Part 121 (Operating Requirements: Domestic, Flag, and Supplemental Operations, 2015) could employ first officers who held a Commercial Pilot certificate, without any minimum age or specified flight hours beyond the requirements for the Commercial Pilot certificate. The new law dramatically changed the requirements for entry-level air carrier pilots; it required first officers to possess the Airline Transport Pilot (ATP) certificate with minima of 1,500 flight hours and 23 years of age.

In 2010 and 2012, teams of Pilot Source Study researchers, reacting to these changes and their potential impact, collected convenience sample data from regional airlines on the source characteristics (background) of newly hired pilots and the subsequent performance of those pilots in air carrier operations, in the era before the new law (Smith, Bjerke, NewMyer, Niemczyk, \& Hamilton, 2010; Smith et al., 2013). At the time of publication, the 2010 and 2012 research helped answer the following questions: Where do regional pilots come from? How were they originally trained? And, once hired, how did they perform? The research conducted in 2010 and 2012 (Pre-Law) serves as a benchmark for comparison with the same questions about pilots in the era after the new law took effect (Post-Law).

In January, 2015, representatives at the Pilot Supply and Demand Summit (Roddey, 2015) discussed the need for a new Pilot Source Study to examine the background, qualifications, and performance of new first officers (PostLaw pilots hired after the August 1, 2013 effective date of Public Law 111-216). During the summer of 2015, when Public Law 111-216 and the related Federal Aviation Administration (FAA) regulation, Pilot Certification and Qualification Requirements for Air Carrier Operations (FOQ Rule) (FAA, 2013, July 15), had been in place for approximately two years, members of the research team traveled across the US from April to October, 2015 and visited 19 Part 121 regional airlines and three Part 135 regional airlines. Extensive background, training, and operational data were collected from de-identified airline records of over 7,000 pilots hired since the new law took effect. The resulting effort represents the largest and most detailed investigation of entry-level airline pilots conducted to date. This article is the third in a series of reports on those datasets, collectively known as the Pilot Source Study 2015.

In the first report of the Pilot Source Study 2015 (Bjerke et al., 2016), the researchers described the backgrounds of pilots hired by the 19 Part 121 regional airlines since August 1, 2013-the date Public Law 111-216 became effective. This first report detailed the backgrounds of airline pilots hired in the Post-Law era and compared their backgrounds to those of pilots hired in the Pre-Law era. The second report (Smith, G. et al., 2016) examined the performance of the Post-Law new-hire pilots as they began their airline careers, following them from their initial airline training through becoming fully qualified regional airline pilots. This third report compares the performance of the Pre-Law pilots (using data from Smith et al., 2010; 2013) with the Post-Law pilots (using data from Smith, G. et al., 2016) who were subject to the new Part 121 pilot hiring rules. When PL 111-216 went into effect and the true implications were realized, many industry professionals registered concerns about unintended consequences of the Public Law that could have an adverse effect on training and the pilot supply. This report provides data and analyses to investigate 
the following basic questions: How has PL 111-216 affected the pilot training and hiring environment? How has PL 111216 affected the costs to the regional airlines of training today's pilots? Which group has performed better: the PreLaw pilots or the Post-Law pilots?

Data collected for each of the Pilot Source Studies came solely from de-identified airline records; no pilots were contacted, interviewed, or surveyed. An important fact is that airlines are not required to maintain detailed records of individual pilot performance; many airlines retain only the minimum information required by the FAA. As a result, information in airline training records differs widely among airlines. When data from numerous airlines are combined into one dataset, many of the records' details are lost because of the non-uniformity among the records. As a result, paucity of data is sometimes a deterrent to comprehensive data collection and analysis.

All of the Pilot Source Studies (2010, 2012, and 2015) have important limitations. The researchers collected background and performance data on pilots who were hired by the regional airlines, both Pre-Law and Post-Law. These data were analyzed as source studies, not supply studies. No attempt was made to predict future pilot supply. Moreover, the researchers made no predictions or assumptions related to the future performance of these pilots in line operations, based on the data collected on pilot background and performance during regional airline new-hire classes.

\section{Research Question}

The first report of Pilot Source Study 2015 (Bjerke et al., 2016) described the backgrounds of the Post-Law pilots and compared them to the backgrounds of Pre-Law pilots. The second report (Smith, G. et al., 2016) analyzed the performance of the Post-Law pilots in airline training and operating experience to determine whether there was a difference in pilot performance, based on their backgrounds. This third report is a comparison of the pilot outcomes between the Pre-Law data (Pilot Source Study 2010 and 2012) and the Post-Law data (Pilot Source Study 2015) to determine whether the background variables had a stronger effect on Pre-Law outcomes or Post-Law outcomes. Thus, this study sought to answer the following research question:

- In Part 121 regional airlines, how does the success of the Post-Law pilots compare to the success of the PreLaw pilots-considering the differences in their background characteristics?

\section{Review of the Literature}

In February of 2009, Colgan Air Flight 3407 crashed in Buffalo, New York, resulting in 49 fatalities aboard the airplane and one fatality on the ground (NTSB, 2010). The NTSB determined that the probable cause of the accident was the captain's inappropriate response to the activation of the stick shaker, which led to an aerodynamic stall from which the airplane did not recover (NTSB). Public Law 111-216, the Airline Safety and Federal Aviation Administration Extension Act of 2010, was unanimously passed by Congress in the aftermath of the 2009 crash and signed by President Obama on August 1, 2010. The resulting FAA Regulation (FAA, 2013, July 15), FOQ Rule, went into full effect on August 1, 2013. Public responses to the law have been generally positive. The Families of Continental Flight 3407 (Families, 2016), representing families directly affected by the crash, have expressed their approval of the law and publicize their roles in influencing its passage. Prior to passage of the law, the Air Line Pilots Association (ALPA), International (Air Line Pilots Association [ALPA], 2012) released a document praising the FAA Notice of Proposed Rulemaking regarding the eventual passage of PL 111-216. In addition, the Allied Pilots Association (APA) has also been a strong proponent for the law, stating: "APA was an aggressive advocate for increasing minimum standards for first officers, which became law last year" (Allied Pilots Association [APA], 2014, p. 1).

A number of papers have been published in response to congressional action leading up to PL 111-216, including a series of Pilot Source Studies similar to the research reported herein. The overarching goal of these studies has been to understand how pilot backgrounds affect their performance in the regional airlines. The first "Pilot Source Study 2010" (Smith et al., 2010) found that "[s]tatistically, the best performing pilots were those who had flight instructor certificates, graduated from collegiate accredited flight programs, received advanced (post-private) pilot training in college, graduated with collegiate aviation degrees (any aviation discipline), and had between 500 and 1,000 preemployment flight hours" (p. 73). The second "Pilot Source Study 2012" (Smith et al., 2013) continued the work from Smith and colleagues (2010) with a different dataset and reached similar conclusions.

In January 2015, a Pilot Supply and Demand Summit was held at Daytona Beach, Florida to assess the impact of PL 111-216 on regional airline pilot hiring (Roddey, 2015). The Summit was attended by representatives from regional airlines, major airlines, government, and academia, who determined that the Pilot Source Study should be repeated to investigate the impact of PL 111-216 on pilot hiring and training in U.S. regional airlines. The new research project, Pilot Source Study 2015, was commissioned to compare the backgrounds of new-hire regional airline first officers who were hired prior to implementation of PL 111-216 to those of first officers hired after that law came into effect. The first report of Pilot Source Study 2015 (Bjerke et al., 2016) compared the background characteristics of pilots hired before and after PL 111-216. The second report of Pilot Source Study 2015 (Smith, G. et al., 2016) investigated the performance of the new group of pilots hired after 
PL 111-216 became effective. Smith, G. and colleagues (2016) utilized four performance measures for this group of pilots: Non-Completions, Extra Training, Extra Initial Operating Experience (IOE), and Extra Recurrent Training. Smith, G. and colleagues (2016) found that "pilots who had the fewest Non-Completions and required less Extra Training were recent college graduates (less than or equal to 4 years since graduation), pilots with lower total flight times (1,500 flight hours or less), and pilots who graduated from flight programs accredited by the Aviation Accreditation Board International (AABI)" (p. 2).

The U.S. aviation industry is beginning to experience the consequences of an issue widely disputed among industry professionals - a pilot shortage. Regional airlines are beginning to discontinue service to smaller cities, including those subsidized by the FAA Essential Air Service (EAS) program (Silk, 2016, January 19). Regional airline pilots are now being hired by the major carriers, and the regional airlines are having difficulty hiring qualified pilots to fly the aircraft that have serviced these cities in the past (Silk, 2016, January 19). The impact of this pilot shortage is exemplified by the recent filing for Chapter 11 reorganization by Republic Airways Holdings, owner of both Republic Airline and Shuttle America Corporation. In their press release, Republic's chairman, president, and CEO, Bryan Bedford, stated one of the reasons for the bankruptcy filing was the loss of revenue from aircraft groundings due to the lack of pilot resources (Church, Schlangenstein, \& Sasso, 2016, February 26). The reason for this shortage is a subject with multiple opinions among industry stakeholders. ALPA (2016) places the regional airlines at fault because of their low compensation. McGee (2015), using a comprehensive supply-and-demand model of U.S. pilots, found "there will not be a civilian system-wide pilot shortage in the near-term, though the system will become strained. Low-paying airlines will continue to have difficulties finding qualified pilots" (p. iii). Salaries of regional airline pilots are not simple to change; they are curtailed by contracts between regional airlines and their mainline carrier partners and by pilot collective bargaining agreements ("The Coming U.S. Pilot Shortage Is Real," 2015). The opposing opinion argues the problem is a shortage of pilots due to a combination of the effects of PL 111216, retiring pilots, U.S. pilots flying for foreign carriers, and an expanding industry (Silk, 2016, January 4). In a study forecasting airline pilot demand, Higgins, Bjerke, Lovelace, and Leonard (2016) noted that the larger major carriers are not likely to experience any shortage in the next three years; however, the regional carriers already have indications of a pilot shortage. According to Higgins and colleagues (2016), the current forecast calls for a shortage of over 14,000 major airline pilots in the US between 2016 and 2026.

The implementation of PL 111-216 has had major impacts on airline pilot hiring. The new law requires that all pilots utilized for Part 121 Scheduled Airline Operations possess an Airline Transport Pilot (ATP) certificate, which requires 1,500 total flight hours, compared to a Commercial Pilot certificate that requires 250 flight hours for certification. The $F O Q$ Rule has provided exceptions to the 1,500 total flight hours requirement. The flight hours are reduced to a minimum of 1,250 for graduates completing an associate or bachelor's aviation degree with at least 30 credits of approved coursework from an approved school; 1,000 flight hours for graduates completing an aviation bachelor's degree with at least 60 credits of an approved curriculum from an approved school; and 750 flight hours for military pilots (FAA, 2013, July 15).

While ALPA (2016) may argue that qualified pilots exist to fill these positions, the U.S. Government Accountability Office (GAO) (U.S. General Accountability Office [GAO], 2014) noted that the large pool of ATP certificate holders can include pilots who are not available, not suitable, or not competent. Moreover, university pilot programs appear to be experiencing a decline in enrollments and graduations (GAO, 2014). These pilot training programs are essential to maintain the pilot supply and subsequently the U.S. aviation industry. Depperschmidt, Bliss, and Casebolt (2015) reported that collegiate aviation training institution respondents to a survey were "concerned that as a result of PL 111-216, programmatic and training costs will increase, recruitment and retention of student pilots will be adversely affected, and overall, the law will be detrimental to collegiate aviation flight training programs" (p. 1). If the pipeline has indeed been damaged, it is imperative for the aviation industry to understand why and repair the damage before the industry (and the traveling public) feels the full effect.

With the passing of PL 111-216, the pilot supply pipeline has been tasked with overcoming a demanding hurdle at an inopportune time, when air travel is expanding and a generation of pilots is retiring at an increasing rate (Creedy, 2016, February 4). Boeing (2015) forecasted a need for 558,000 new pilots worldwide by 2034, and the International Civil Aviation Organization (ICAO) estimated a new pilot deficit of 160,000 by 2030 , due to lack of training capacity (International Civil Aviation Organization [ICAO], 2011).

A career as an airline pilot has been regarded as one of the most respected professions since the invention of the airplane. Most pilots are very passionate about their profession. The flight environment is always different; it is stimulating, interesting, and can be extremely rewarding (The Truth about the Profession, 2016). Moreover, airline pilots can enjoy travel benefits for themselves and their families with the possibility of free, or nearly free, travel by air. However, low pay, high academic debt, and quality of life issues can dissuade people from pursuing a career as an airline pilot (Carey, 2015).

Because of the acute shortage of qualified pilots, several regional airlines have been offering signing and retention 
bonuses. Templeton (2016) noted that some regional airlines were offering $\$ 5,000$ toward tuition reimbursement and $\$ 6,000$ as a retention bonus. Several airlines are offering signing bonuses, ranging from $\$ 5,000$ to $\$ 12,500$. One airline is offering an $\$ 80,000$ four-year pilot retention program (Templeton, 2016).

Several regional airlines have been developing pipeline programs with flight schools and colleges across the country. Candidates for these programs who have earned a Commercial Pilot certificate and instrument rating can be interviewed while still in school (Envoy, 2016). If selected, candidates are considered hired by the airline and enter a structured path toward the regional airline, usually by building flight hours as flight instructors until they meet the airline's minimum flight hour requirement. The candidates accepted to the programs are offered tuition reimbursement, placement as flight instructors, and other support as they reach various certification milestones. Tuition reimbursement can ultimately reach up to $\$ 16,000$ (Silk, 2016, January 22). When the minimum requirements are met, candidates are placed in the next available airline ground school and are usually offered bonus compensation for joining the airline. Some regional airlines also offer nointerview, seniority-based promotions toward major airlines (Silk, 2016, January 22).

As one example of a pipeline program, JetBlue Airways is planning to offer an $a b$ initio pilot training program (Schlangenstein, 2015). JetBlue will hire individuals selected for this program with no pilot experience and train them to become professional pilots. Recruits must take academic classes at JetBlue before moving to a partner company to gain the required 1,500 flight hours. They will then return to New York-based JetBlue, or can apply at another airline. Prospective pilots would pay for their own training. The pilot unions are opposed to JetBlue's initiative, claiming "there are thousands of pilots available that have higher qualifications right now than any pilot coming out of an ab initio program" (Schlangenstein, 2015, p. 1).

Whether a pilot shortage exists or not continues to be debated. To resolve this controversy, there is a need for an empirical study to determine the pilot supply for regional airlines. The Pilot Source Studies are not pilot supply studies. These distinct studies have many differences; most notably, they have categorically different populations. The population of a pilot supply study for regional airlines would consist of all pilots eligible to be hired by any regional airline. The population of the Pilot Source Studies consists of pilots already hired by a regional airline.

\section{Methodology}

In the first report of Pilot Source Study 2015, Bjerke and colleagues (2016) described the data collection methods for the Post-Law dataset in detail. A brief summary of the methodology is repeated in this third report. The Pilot
Source Study 2015 (titled the Post-Law study to distinguish it from the 2010/2012 Pre-Law Pilot Source Studies) originated from the January 2015 Pilot Supply and Demand Summit (Roddey, 2015) at which representatives from the regional airlines, major airlines, government, and academia identified a need for an empirical study of the effects of PL 111-216 on pilot hiring and pilot training in U.S. regional airlines. This study was originally designed as a convenience sample of the airlines that participated in the Pre-Law studies; however, airline representatives at the May 2015 Regional Airline Association (RAA, 2015) Convention in Cleveland, $\mathrm{OH}$ were so receptive that this study was redesigned as a population study - to collect data at all of the U.S. regional airlines on all pilots hired after August 1, 2013. From April to October, 2015, a team of data collectors visited 22 U.S. regional airlines (19 Part 121 airlines and three Part 135 airlines) and collected 7,081 records of pilots hired since the effective date of PL 111-216. Data collectors extracted data from human resource records (applications, resumes, etc.) that are the independent variables - the background (source) or predictor variables in the Pilot Source Study 2015. Data collectors also extracted data from training records and operational records that are the dependent variables-the outcome or success variables in the Pilot Source Study 2015. The two elements that enabled data collection were (a) a nondisclosure agreement that guaranteed the data would not be used for any purpose other than the Pilot Source Study 2015, and (b) the de-identification of all data that required the data collection manager to remove all identifying information (name, ID number, gender, age, ethnicity, etc.) from the data before it was released by the airline.

The datasets from the 19 Part 121 airlines are the subject of articles 1, 2, and 3 of the Pilot Source Study 2015. The datasets from the three Part 135 airlines are the subject of Article 4 of the Pilot Source Study 2015. Since pilot records are not standardized across airlines, the task following data collection was to consolidate the 19 disparate datasets into a single dataset for analysis. In combining datasets, some granularity was lost by merging and coding data from dissimilar data collected at the regional airlines. The data were analyzed by seven researchers; each has a scholarly record and a principled reputation. The researchers individually analyzed the data and negotiated the differences in weekly conference calls until there was consensus on the results. The intent is to publish the four articles of the Pilot Source Study 2015 in an open access, peer-reviewed academic journal and to inform stakeholders of the results. The stakeholders for this study are those who passed PL 111-216 and those affected by it; namely, the U. S. Congress, the FAA, the U. S. regional airlines, and the public.

\section{Results}

Article 1 of the Pilot Source Study 2015 (Bjerke et al., 2016) analyzed the background characteristics of Part 121 
regional airline pilots hired since the enactment of PL 111216 (Post-Law pilots) and compared their background characteristics to the Part 121 regional airline pilots hired before the enactment of PL 111-216 (Pre-Law pilots). Article 2 of the Pilot Source Study 2015 (Smith, G. et al., 2016) determined how the background characteristics of Post-Law pilots affected their performance (outcomes) at a Part 121 regional airline by analyzing four outcome variables: Non-Completions, Extra Training, Extra IOE, and Extra Recurrent Training. This report (Article 3 of the Pilot Source Study 2015) compares the pilot outcome variables between the Pre-Law dataset and the Post-Law dataset to determine whether the background variables had a stronger or diminished effect on Post-Law outcomes. Statistical analyses were conducted to determine (a) if there was a difference in pilot training success since the enactment of the FOQ Rule, and (b) to determine which of the background characteristics had more effect on these outcomes. Three outcome variables were comparable between the Pre-Law dataset and the Post-Law dataset: Extra Training Events, Completions, and IOE z-Score. Insufficient data were available to compare the Recurrent Training outcome variable.

\section{Background Variables-Overview}

Figure 1 displays the significant differences between the Pre-Law and Post-Law pilots with four demographic background variables: AABI-Accredited Flight Program, Aviation Degree, Military Pilot, and CFI Certificate. The detailed results are

- AABI Flight Degree is significantly different $(N=$ $\left.10,912, \chi^{2}(1)=122.15, p<.001, \Phi=-.106, p<.001\right)$; with $32 \%$ of the Pre-Law pilots having AABI Flight Degrees and only $23 \%$ of the Post-Law pilots having AABI Flight Degrees,

- Aviation Degree is significantly different $(N=10,631$, $\left.\chi^{2}(1)=233.38, p<.001, \Phi=-.148, p<.001\right)$; with $66 \%$ of the Pre-Law pilots having an Aviation Degree and only $51 \%$ of the Post-Law pilots having an Aviation Degree,

- Military Pilot is significantly different $(N=12,638$, $\left.\chi^{2}(1)=380.97, p<.001, \Phi=.174, p<.001\right)$; with $3 \%$ of the Pre-Law pilots being Military Pilots and $12 \%$ of the Post-Law pilots being Military Pilots, and

- CFI Certificate is significantly different $(N=12,806$, $\left.\chi^{2}(1)=40.13, p<.001, \Phi=-.056, p<.001\right)$; with $82 \%$ of the Pre-Law pilots having their CFI Certificate and only $78 \%$ of the Post-Law pilots having their $C F I$ Certificate.

Figure 2 displays the significant differences between Previous Experience for the Pre-Law and Post-Law pilots: $N=10,777, \chi^{2}(2)=71.68, p<.001$, Cramer's $V=.082$, $p<.001$. The pilots in the Post-Law data had an extensive array of non-aviation related Previous Experience, including small business owners, real estate professionals, lawyers, mechanics, etc.; thus, many of the Post-Law pilots are likely to be career changers. For Previous Experience, significant differences were found for Corporate Pilots and Flight Instructors.

- $15 \%$ of the Pre-Law pilots were Corporate Pilots and $20 \%$ of the Post-Law pilots were Corporate Pilots, and

- $53 \%$ of the Pre-Law pilots listed their Previous Experience as a Flight Instructor, and $46 \%$ of the Post-Law pilots listed their Previous Experience as a Flight Instructor.

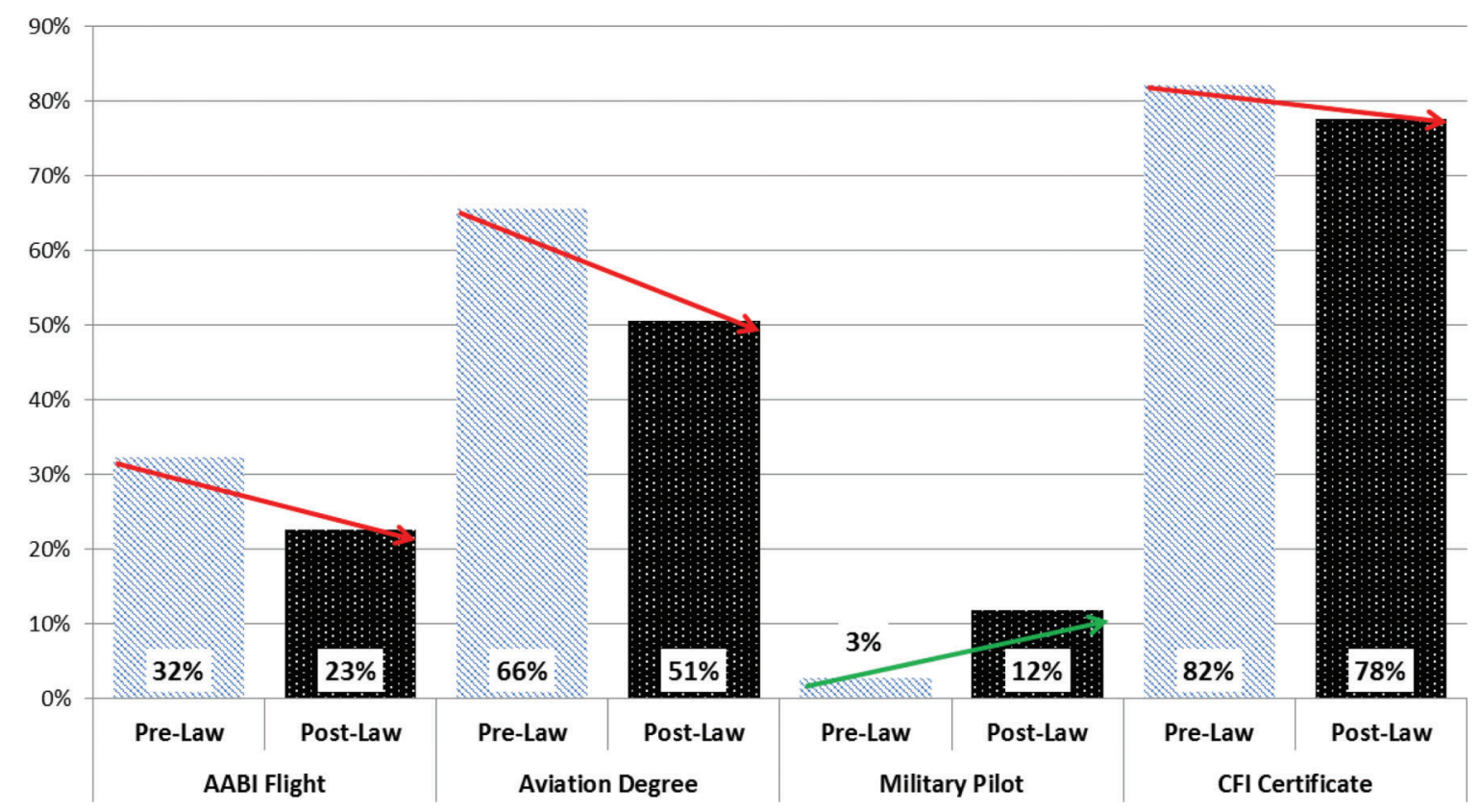

Figure 1. Significant demographic variables. 


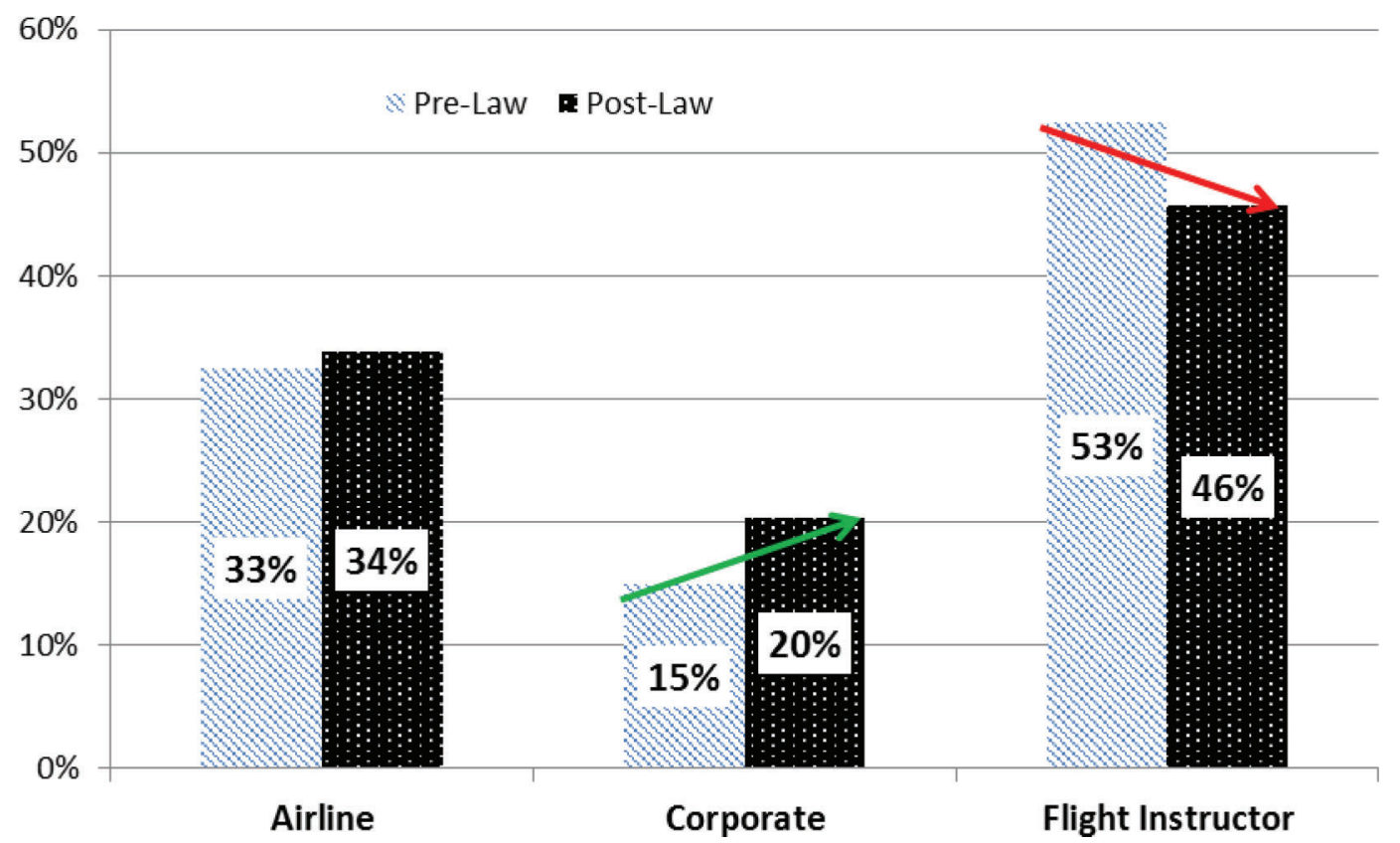

Figure 2. Distribution of Previous Experience.

Significant differences were found between the Pre-Law and Post-Law pilots in the experience background variables, Dual Given and Total Flight Hours. The mean of Pre-Law Dual Given hours was 689; the mean of Post-Law Dual Given hours was 940. The significant increase in Dual Given hours could be attributed to PL 111-216; pilots used flight instruction hours to bridge the extended gap and to accrue sufficient flight hours to be hired by a Part 121 regional airline. The mean Pre-Law Total Flight Hours was 1,597; the mean Post-Law Total Flight Hours was 3,071. The significantly higher Post-Law Total Flight Hours is a direct result of PL 111-216.

\section{Outcome Variable-Extra Training Events}

Using an ANOVA, the Pre-Law pilots had significantly fewer Extra Training Events (mean $=.52 ; N=6,608$ ) compared to the Post-Law pilots' Extra Training Events (mean $=1.20 ; N=5,118$ ). The Levene test for homogeneity of variance was significant. The two groups had unequal variances: $W(1,11,184)=464.45, p<.001$; therefore, the Brown-Forsythe test for unequal variances is reported: $F(1,7,528)=240.52, p<.001$ (see Figure 3 ).

The variable, Extra Training Events, was also tested as the dependent variable using regression analyses. The following independent variables were not able to predict the number of Extra Training Events: College Degree, Aviation Degree, Military Pilot, Previous Experience, CFI Certificate, or Dual Given. The regression analysis was significant for AABI Flight Degree and Total Flight Hours; however, the value of $R^{2}(=.009)$ indicates that these variables predicted less than $1 \%$ percent of the variance for Extra Training Events. For all practical purposes, regression analysis cannot help the airlines predict who will require extra training.

A new dichotomous variable was created for Extra Training Events; the new variable is Extra Training Events Category, for which options are (a) zero extra training events, or (b) one or more extra training events. Using the chi-square test of significance, there was a significant difference between the Pre-Law and Post-Law outcomes: $N=11,186, \chi^{2}(1)=247.85, p<.001, \Phi<.149, p<.001$. The Pre-Law pilots had more than expected zero Extra Training Events, while the Post-Law pilots had more than expected one or more Extra Training Events. Therefore, the Post-Law pilots required significantly more extra training (see Figure 4).

In the following figures, bolded borders indicate significance, a plus (+) sign indicates a positive outcome, and the colors of the arrows indicate the result of the Pre-Law and Post-Law comparison. A red arrow indicates a negative effect and a green arrow indicates a positive effect from Pre-Law to Post-Law. A solid arrow indicates a significant effect to a significant effect, and a dashed arrow indicates a non-significant effect to a significant effect, or a significant effect to a non-significant effect.

\section{Pre-Law/Post-Law Extra Training Events With Background Variables}

For the variables Pre-Law/Post-Law and Extra Training Events, the new variable has four categories: Pre-Law: Zero Extra Training Events, Post-Law: Zero Extra Training Events, Pre-Law: One or More Extra Training Events, and Post-Law: One or More Extra Training Events. The following sections will describe how the independent variables 


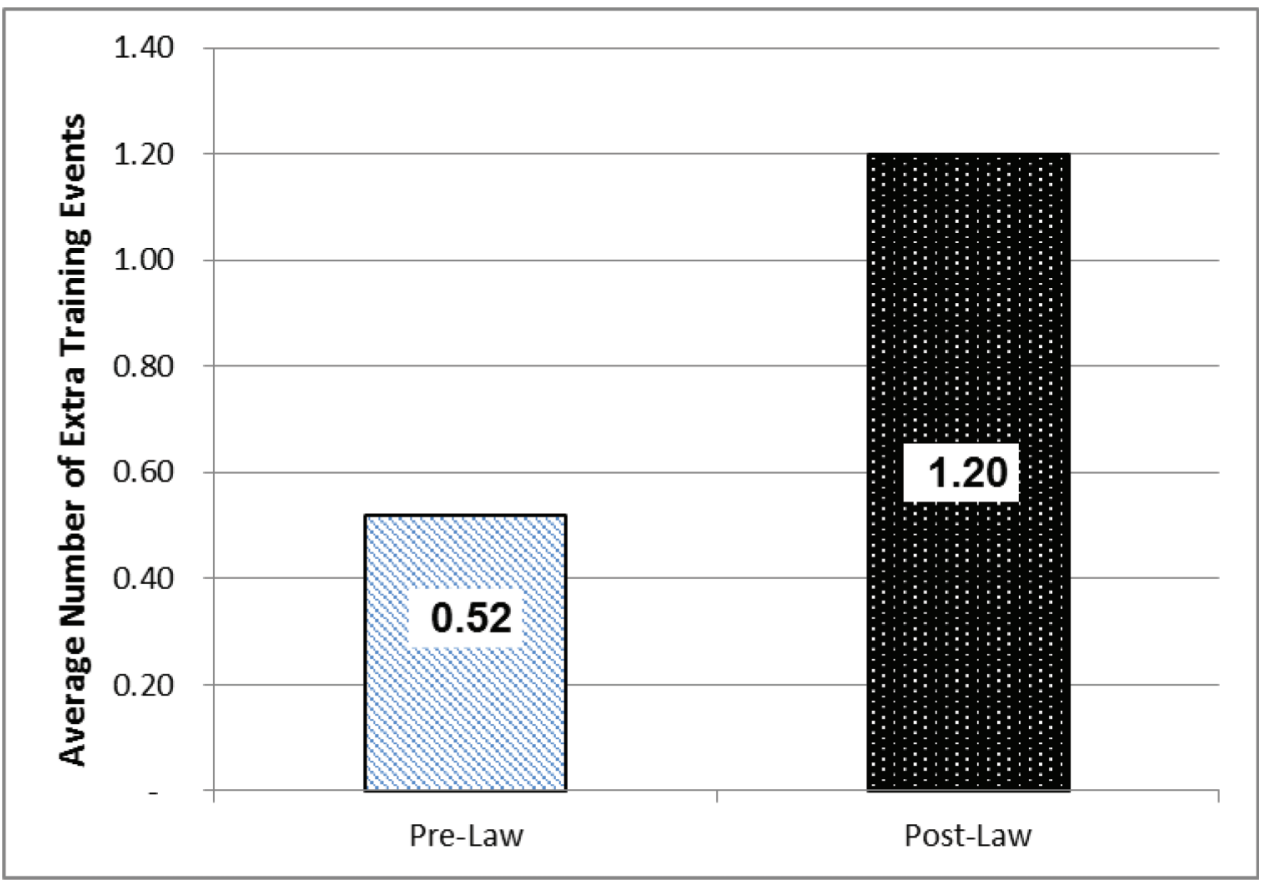

Figure 3. Increase in average Extra Training Events.

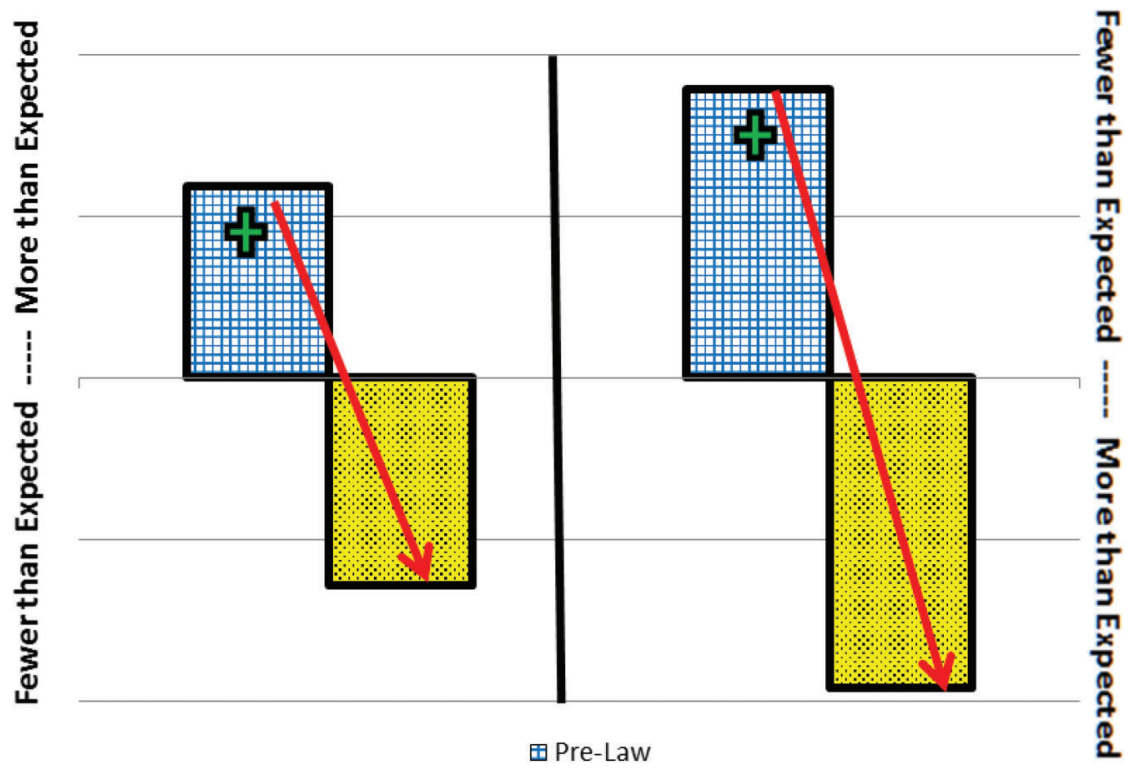

Post-Law

Zero

One or more

Figure 4. Extra Training Events with Pre-Law/Post-Law.

significantly influenced this new combined outcome variable, Pre-Law/Post-Law Extra Training Events.

College Degree With Pre-Law/Post-Law Extra Training Events

Using the chi-square test of significance, College Degree with Pre-Law/Post-Law Extra Training Events was statis- tically significant: $N=11,090, \chi^{2}(6)=37.953, p<.001$; Cramer's $V=.041, p<.001$. Associate Degree increased its negative effect on zero extra training between Pre-Law and Post-Law-yielding fewer Post-Law pilots with zero extra training events. No Degree increased its negative effect on one or more extra training events between PreLaw and Post-Law-yielding more Post-Law pilots with 
one or more extra training events. The following cells had significant contributions to the chi-square, as displayed in Figure 5.

- For Post-Law-Zero Extra Training Events: Pilots with an Associate Degree had significantly fewer zero extra training events than expected: Observed $=243$ versus Expected $=292.7$; Chi-square contribution $=$ $22 \%$.

- For Pre-Law-One or More Extra Training Events: Pilots with an Associate Degree had significantly more one or more extra training events than expected: Observed $=170$ versus Expected $=140.8$; Chi-square contribution $=16 \%$.

- For Post-Law-One or More Extra Training Events: Pilots with No Degree had significantly more one or more extra training events than expected: Observed $=$ 376 versus Expected $=332.1$; Chi-square contribution $=15 \%$.

Aviation Degree With Pre-Law/Post-Law Extra Training Events

Using the chi-square test of significance, Aviation Degree with Pre-Law/Post-Law Extra Training Events was statistically significant: $N=9,105, \chi^{2}(3)=242.788$, $p<.001$; Cramer's $V=.163, p<.001$. Therefore, Aviation Degree lost some of its positive effect on zero extra training between Pre-Law and Post-Law-yielding fewer
Post-Law pilots with zero extra training events. Aviation Degree increased its positive effect on one or more extra training events between Pre-Law and PostLaw-yielding fewer Post-Law pilots with one or more extra training events. The following cells had significant contributions to the chi-square, as displayed in Figure 6.

- For Pre-Law-Zero Extra Training Events: Pilots with a Non-Aviation Degree had significantly fewer zero extra training events than expected: Observed = 1,042 versus Expected = 1,331.7; Chi-square contribution $=26 \%$.

- For Pre-Law-Zero Extra Training Events: Pilots with an Aviation Degree had significantly more zero extra training events than expected: Observed $=2,138$ versus Expected $=1,848.3$; Chi-square contribution $=19 \%$ [positive outcome].

- For Post-Law-One or More Extra Training Events: Pilots with a Non-Aviation Degree had significantly more one or more extra training events than expected: Observed $=1,023$ versus Expected $=784.4$; Chisquare contribution $=30 \%$.

- For Post-Law-One or More Extra Training Events: Pilots with an Aviation Degree had significantly fewer one or more extra training events than expected: Observed $=850$ versus Expected $=1,088.6$; Chisquare contribution $=22 \%$ [positive outcome].

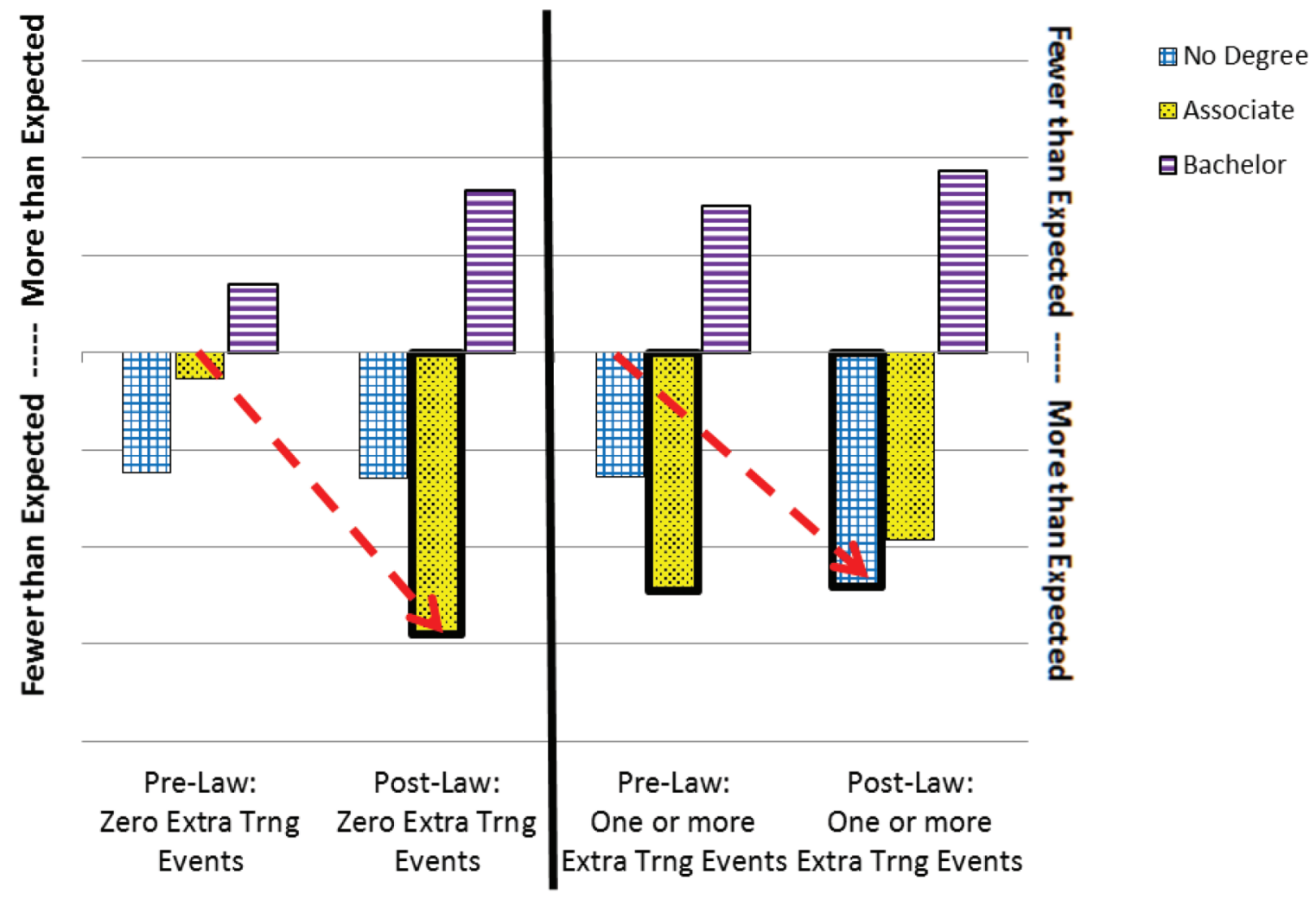

Figure 5. College Degree with Pre-Law/Post-Law Extra Training Events. 

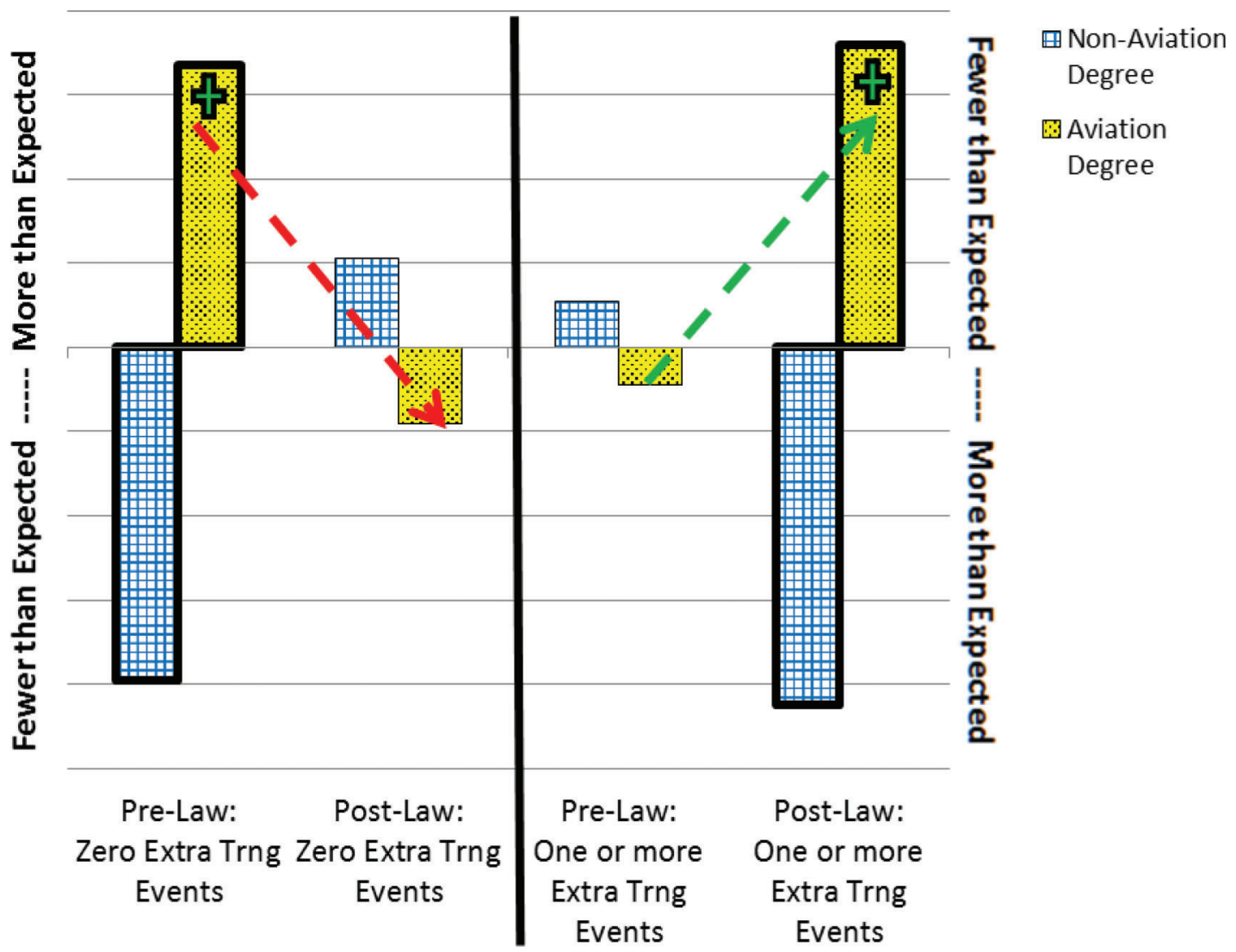

Figure 6. Aviation Degree with Pre-Law/Post-Law Extra Training Events.

AABI Flight Degree With Pre-Law/Post-Law Extra Training Events

Using the chi-square test of significance, AABI Flight Degree with Pre-Law/Post-Law Extra Training Events was statistically significant: $N=9,293, \chi^{2}(3)=165.882, p<$ .001 ; Cramer's $V=.134, p<.001$. Therefore, AABI Flight Degree lost some of its positive effect on zero extra training between Pre-Law and Post-Law-yielding fewer Post-Law pilots with zero extra training events. AABI Flight Degree increased its positive effect on one or more extra training events between Pre-Law and Post-Law-yielding fewer Post-Law pilots with one or more extra training events. The following cells had significant contributions to the chisquare, as displayed in Figure 7.

- For Pre-Law-Zero Extra Training Events: Pilots with a Non-AABI Flight Degree had significantly fewer zero extra training events than expected: Observed $=$ 2,105 versus Expected = 2,298.2; Chi-square contribution $=10 \%$.

- For Pre-Law-Zero Extra Training Events: Pilots with an AABI Flight Degree had significantly more zero extra training events than expected: Observed = 1,075 versus Expected $=881.8$; Chi-square contribution $=26 \%$ [positive outcome].

- For Post-Law-One or More Extra Training Events: Pilots with a Non-AABI Flight Degree had signifi- cantly more one or more extra training events than expected: Observed $=1,626$ versus Expected $=1,420.8$; Chi-square contribution $=18 \%$.

- For Post-Law-One or More Extra Training Events: Pilots with an AABI Flight Degree had significantly fewer one or more extra training events than expected: Observed $=340$ versus Expected $=545.2$; Chi-square contribution $=47 \%$ [positive outcome].

Previous Experience With Pre-Law/Post-Law Extra Training Events

Using the chi-square test of significance, Previous Experience with Pre-Law/Post-Law Extra Training Events was statistically significant: $N=9,579, \chi^{2}(6)=163.385$, $p<.001$; Cramer's $V=.092, p<.001$. Airline experience increased its positive effect on zero Extra Training between Pre-Law and Post-Law-yielding more Post-Law pilots with zero extra training events. Airline experience lost some of its positive effect on one or more extra training events between Pre-Law and Post-Law-yielding fewer Post-Law pilots with one or more extra training events. Corporate experience decreased its negative effect on zero Extra Training between Pre-Law and Post-Law-yielding more Post-Law pilots with zero extra training events. Corporate experience increased its negative effect on one or more extra training events between Pre-Law and 


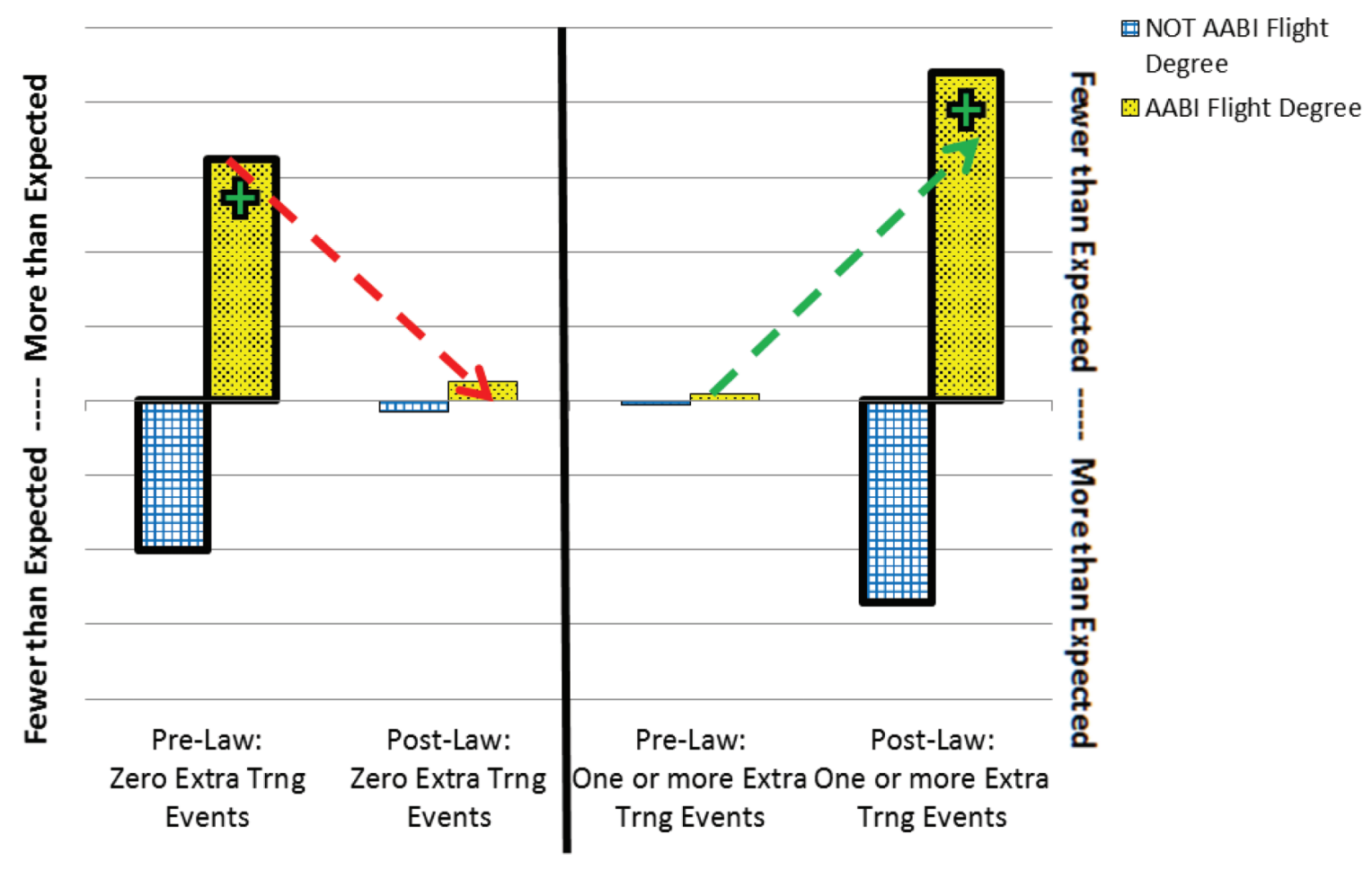

Figure 7. AABI Flight Degree with Pre-Law/Post-Law Extra Training Events.

Post-Law-yielding more Post-Law pilots with one or more extra training events. Flight Instructor experience increased its negative effect on zero Extra Training between Pre-Law and Post-Law-yielding fewer Post-Law pilots with zero extra training events. Flight Instructor experience decreased its negative effect on one or more extra training events between Pre-Law and Post-Law-yielding fewer Post-Law pilots with one or more extra training events. The following cells had significant contributions to the chisquare, as displayed in Figure 8.

- For Pre-Law-Zero Extra Training Events: Pilots whose primary Previous Employment was at an Airline had significantly more zero extra training events than expected: Observed = 1,507 versus Expected = 1,394; Chi-square contribution $=6 \%$ [positive outcome].

- For Post-Law-Zero Extra Training Events: Pilots whose primary Previous Employment was at an Airline had significantly more zero extra training events than expected: Observed $=927$ versus Expected $=$ 827.2; Chi-square contribution $=7 \%$ [positive outcome].

- For Pre-Law-One or More Extra Training Events: Pilots whose primary Previous Employment was at an Airline had significantly fewer one or more extra training events than expected: Observed $=286$ versus Expected $=419.2$; Chi-square contribution $=26 \%$ [positive outcome].

- For Post-Law-One or More Extra Training Events, pilots whose primary Previous Employment was at an Airline had significantly fewer one or more extra training events than expected: Observed $=427$ versus Expected $=506.6$; Chi-square contribution $=8 \%$ [positive outcome].

- For Pre-Law-Zero Extra Training Events: Pilots whose primary Previous Employment was in Corporate aviation had significantly fewer zero extra training events than expected: Observed $=608$ versus Expected $=722.4$; Chi-square contribution $=11 \%$.

- For Post-Law-One or More Extra Training Events: Pilots whose primary Previous Employment was in Corporate aviation had significantly more one or more extra training events than expected: Observed $=$ 345 versus Expected = 262.6; Chi-square contribution $=16 \%$.

- For Post-Law-Zero Extra Training Events: Pilots whose primary Previous Employment was Flight Instructor had significantly fewer zero extra training events than expected: Observed $=1,131$ versus Expected $=1,262$; Chi-square contribution $=8 \%$.

- For Pre-Law-One or More Extra Training Events: Pilots whose primary Previous Employment was Flight Instructor had significantly more one or more extra training events than expected: Observed $=772$ versus Expected $=639.5$; Chi-square contribution $=17 \%$.

CFI Certificate With Pre-Law/Post-Law Extra Training Events

Using the chi-square test of significance, CFI Certificate with Pre-Law/Post-Law Extra Training Events were statistically significant: $N=11,186, \chi^{2}(3)=58.93, p<.001$; 


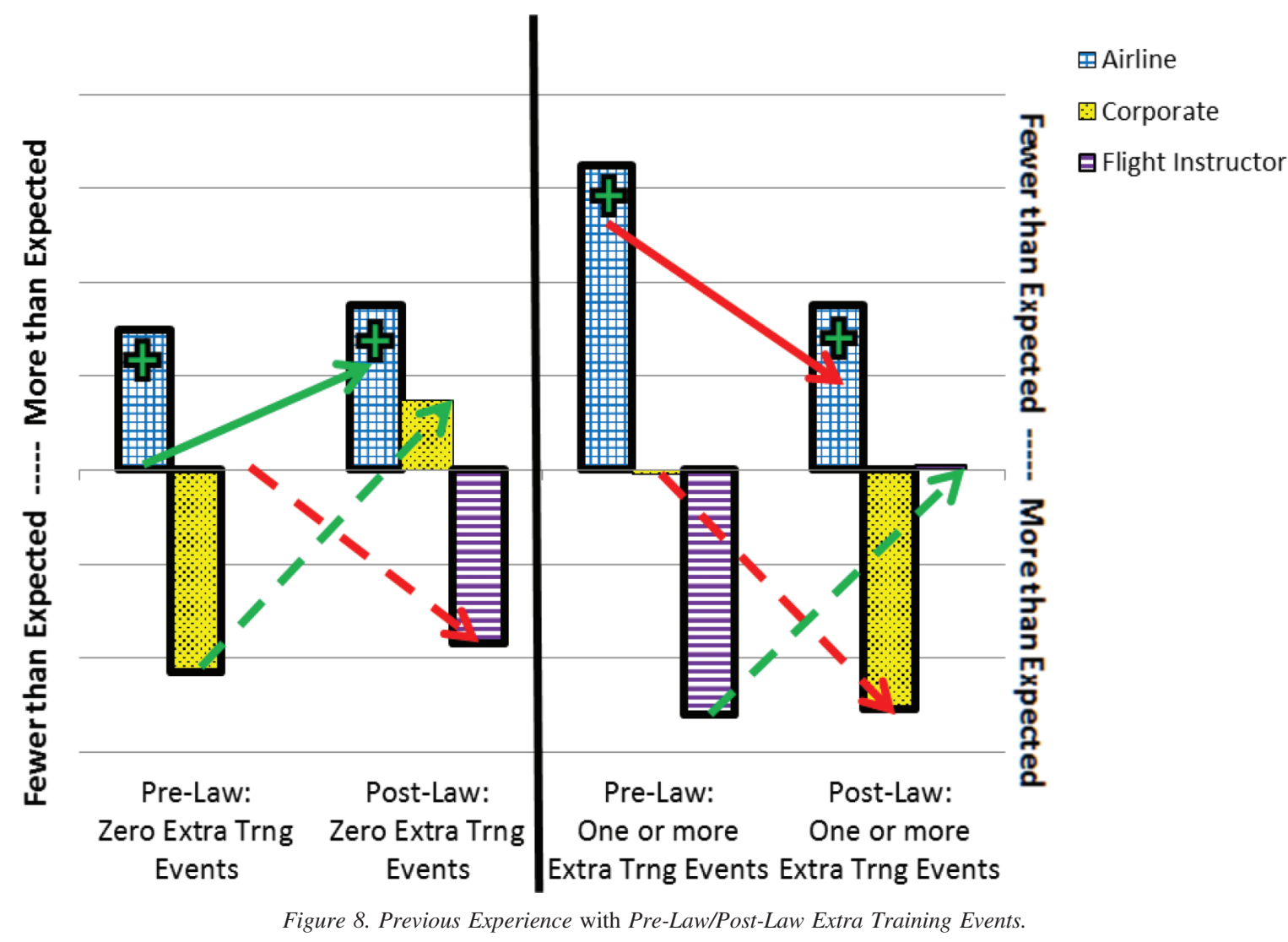

Cramer's $V=.073, p<.001$. CFI Certificate lost some of its positive effect on zero Extra Training between Pre-Law and Post-Law-yielding fewer Post-Law pilots with zero extra training events. CFI Certificate increased its positive effect on one or more extra training events between PreLaw and Post-Law-yielding fewer Post-Law pilots with one or more extra training events. No CFI Certificate increased its effect on zero extra training events between Pre-Law and Post-Law-yielding more Post-Law pilots with zero extra training events. No CFI Certificate lost some of its effect on one or more extra training events between Pre-Law and Post-Law-yielding more Post-Law pilots with one or more extra training events. The following cells had significant contributions to the chi-square, as displayed in Figure 9.

- For Pre-Law-Zero Extra Training Events: Pilots with No CFI Certificate had significantly fewer zero extra training events than expected: Observed $=747$ versus Expected $=874.8$; Chi-square contribution $=32 \%$.

- For Pre-Law-Zero Extra Training Events: Pilots with a CFI Certificate had significantly more zero extra training events than expected: Observed $=3,828$ versus Expected $=3,700.2$; Chi-square contribution $=7 \%$ [positive outcome].

- For Pre-Law-One or More Extra Training Events: Pilots with No CFI Certificate had significantly more one or more extra training events than expected: Observed $=339$ versus Expected $=285.5$; Chi-square contribution $=17 \%$.

- For Post-Law-One or More Extra Training Events: Pilots with No CFI Certificate had significantly more one or more extra training events than expected: Observed $=460$ versus Expected $=375.9$; Chi-square contribution $=32 \%$.

- For Post-Law-One or More Extra Training Events: Pilots with a CFI Certificate had significantly fewer one or more extra training events than expected: Observed $=1,506$ versus Expected $=1,590.1$; Chisquare contribution $=8 \%$ [positive outcome].

Dual Given and Pre-Law/Post-Law Extra Training Events

Using an ANOVA, the means for Dual Given with the factor as Pre-Law/Post-Law Extra Training Events were statistically significant: $N=5,371, F(3,5,371)=80.72$, $p<.001$; a significant difference exists among the four categories. The Levene test for the homogeneity of variance was significant, $W(3,5,371)=38.89, p<.001$; therefore, the Games-Howell post hoc tests for unequal variances were used. Dual Given hours was less beneficial to regional airline training for Post-Law pilots. In the ANOVA post hoc analysis, there were three important results (see Figure 10). 


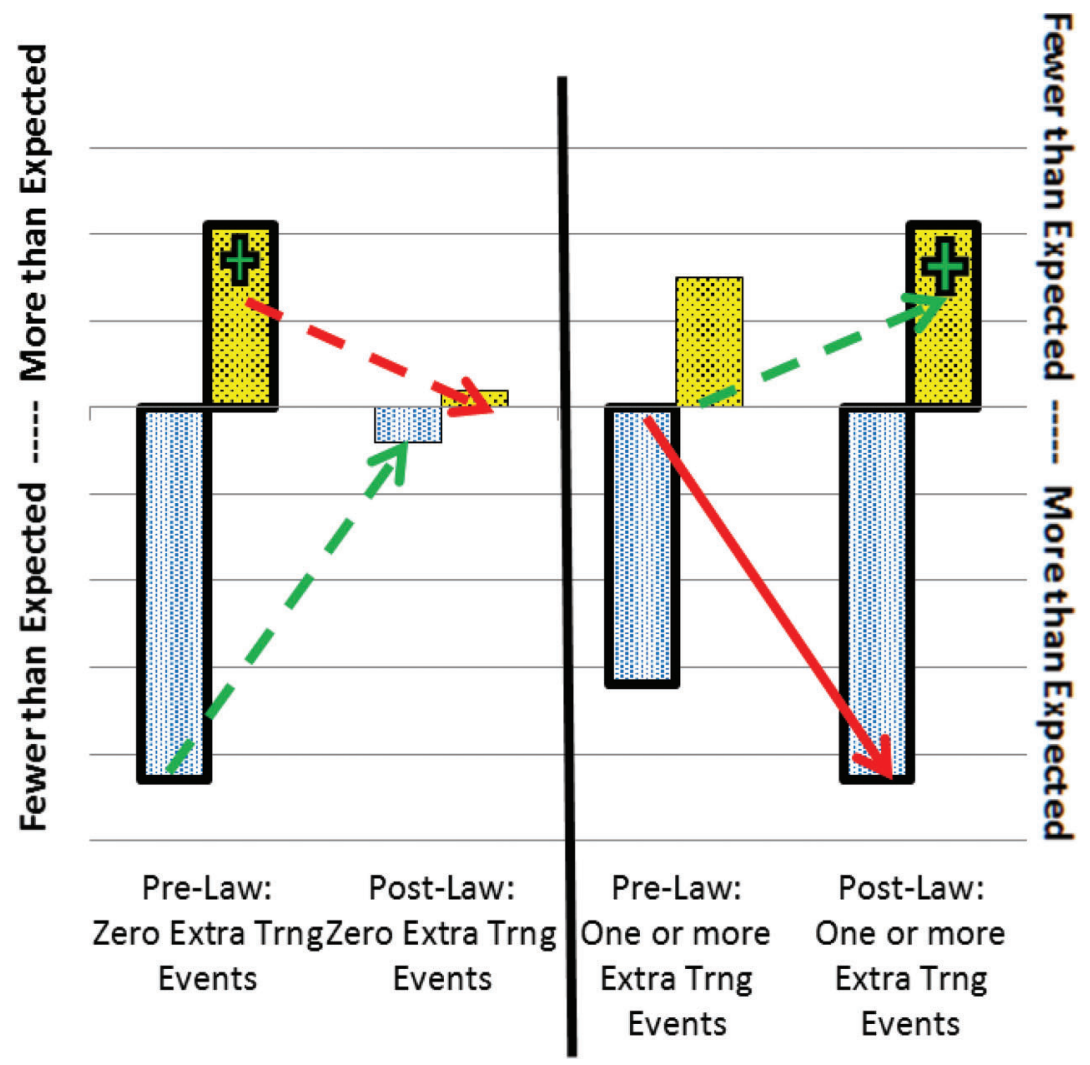

国 Not a CFI

因Yes, CFI

Figure 9. CFI Certificate with Pre-Law/Post-Law Extra Training Events.

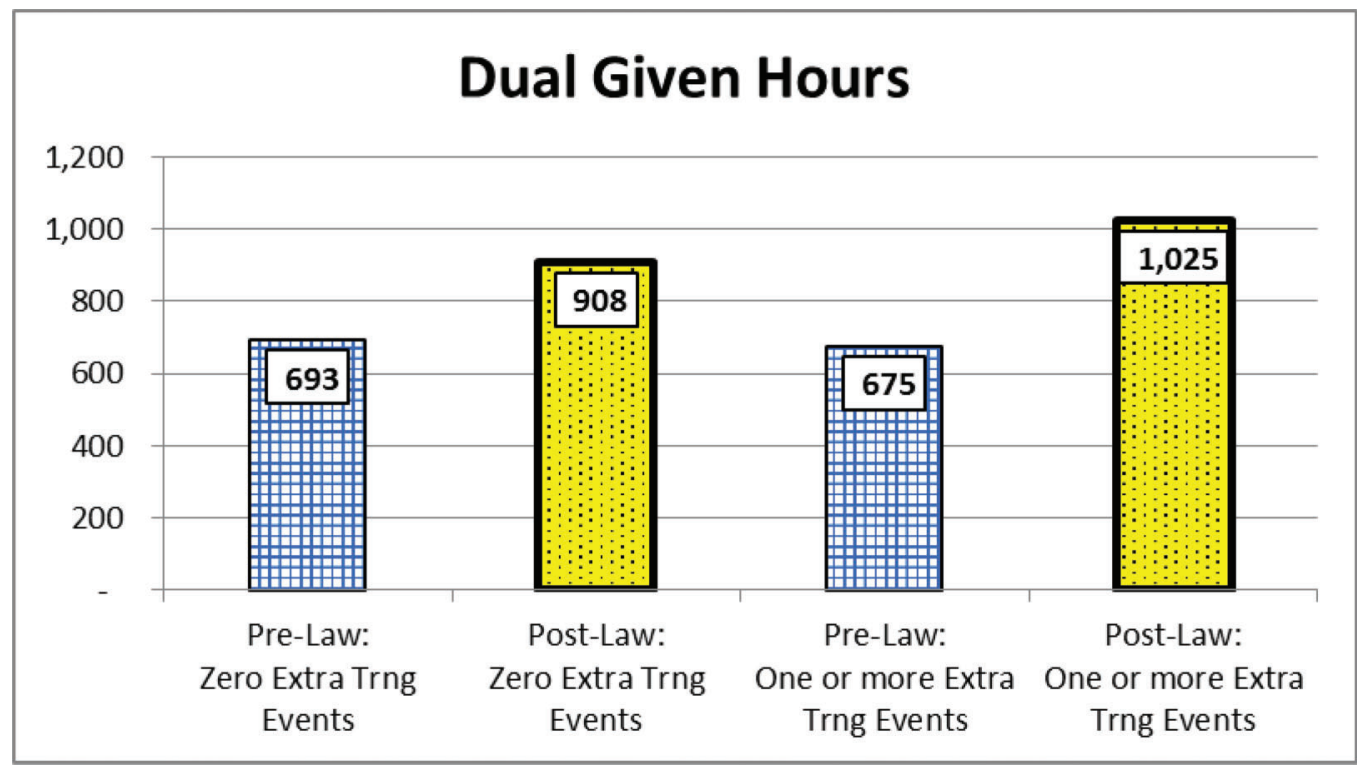

Figure 10. Dual Given with Pre-Law/Post-Law Extra Training Events.

- The Dual Given mean for the Post-Law: Zero Extra Training Events (mean $=908$ hours, $N=1,968$ ) was significantly higher than the Dual Given mean for the Pre-Law: Zero Extra Training Events (mean $=693$ hours, $N=1,768$ ).

- The Dual Given mean for the Post-Law: One or More Extra Training Events (mean $=1,025$ hours;
$N=1,128)$ was significantly higher than the Dual Given mean for Pre-Law: One or More Extra Training Events (mean $=675$ hours, $N=$ 511).

- The Dual Given mean for the Post-Law: One or More Extra Training Events (mean $=1,025$ hours; $N=$ $1,128)$ was significantly higher than the Dual Given 
mean for Post-Law: Zero Extra Training Events (mean $=908$ hours, $N=1,968$ ).

Total Flight Hours and Pre-Law/Post-Law Extra Training Events

Using an ANOVA, the means for Total Flight Hours with the factor as Pre-Law/Post-Law Extra Training Events were statistically significant: $N=11,008, F(3,11,004)=$ $348.21, p<.001$; a significant difference exists among the four categories. The Levene test for the homogeneity of variance was significant, $W(3,11,004)=240.23, p<.001$; therefore, the Games-Howell post hoc tests for unequal variances were used. In light of these results, the additional Total Flight Hours required by the legislation did not have a positive effect on extra training events. As Total Flight Hours increased, the number of extra training events also increased-the result is a significant positive correlation (Spearman's rho $=.256, p<.001$ ). In the ANOVA post hoc analysis, there were two important results (see Figure 11).

- The Total Flight Hours mean for the Pre-Law: Zero Extra Training Events (mean $=1,647$ hours, $N=4,487$ ) was significantly lower than the Total Flight Hours mean for Post-Law: Zero Extra Training Events (mean $=2,896$ hours, $N=3,126$ ).

- The Total Flight Hours mean for the Pre-Law: One or More Extra Training Events (mean $=1,439$ hours, $N=$ 1,449) was significantly lower than the Total Flight Hours mean for Post-Law: One or More Extra Training Events (mean $=3,103$ hours, $N=1,946$ ).

\section{Completions}

Using the chi-square test of significance, the Pre-Law pilots had significantly more Completions (mean $=93.44 \%$; $N=6,070)$ compared to the Post-Law pilots (mean = 83.57\%; $N=5,514): N=11,584, \chi^{2}(1)=281.991, p<$ $.001, \Phi=-.156, p<.001$ (see Figure 12). The Pre-Law pilots had more completions (Observed $=5,672$ ) than expected $($ Expected $=5,386)$ and fewer non-completions (Observed $=398)$ than expected $($ Expected $=683)$. Comparing the Pre-Law results with the Post-Law results, the Post-Law pilots had fewer completions (Observed $=4,608$ ) than expected (Expected $=4,893$ ) and more non-completions (Observed $=906)$ than expected $($ Expected $=621)$. Overall, the Post-Law pilots have $9.87 \%$ fewer completions than the Pre-Law pilots.

A discriminant analysis was conducted to determine the extent to which the following variables could accurately predict membership in the Completions groups (Yes or No). For the independent variables $A A B I$ Flight Degree, Aviation Degree, CFI Certificate, Total Flight Hours, Extra Training Events, and a constant, the discriminant analysis function will classify $78 \%$ of the original grouped cases. Notably, the data have significant multivariate normalitythe independent variables are not normally distributed, which violates one of the assumptions of discriminant analysis $(N=9,040$, Box's $M(15,4,812,135.8)=762.08$; $p<.001)$; the violation of this assumption was expected because three independent variables, AABI Flight Degree, Aviation Degree, and CFI Certificate, are dichotomous

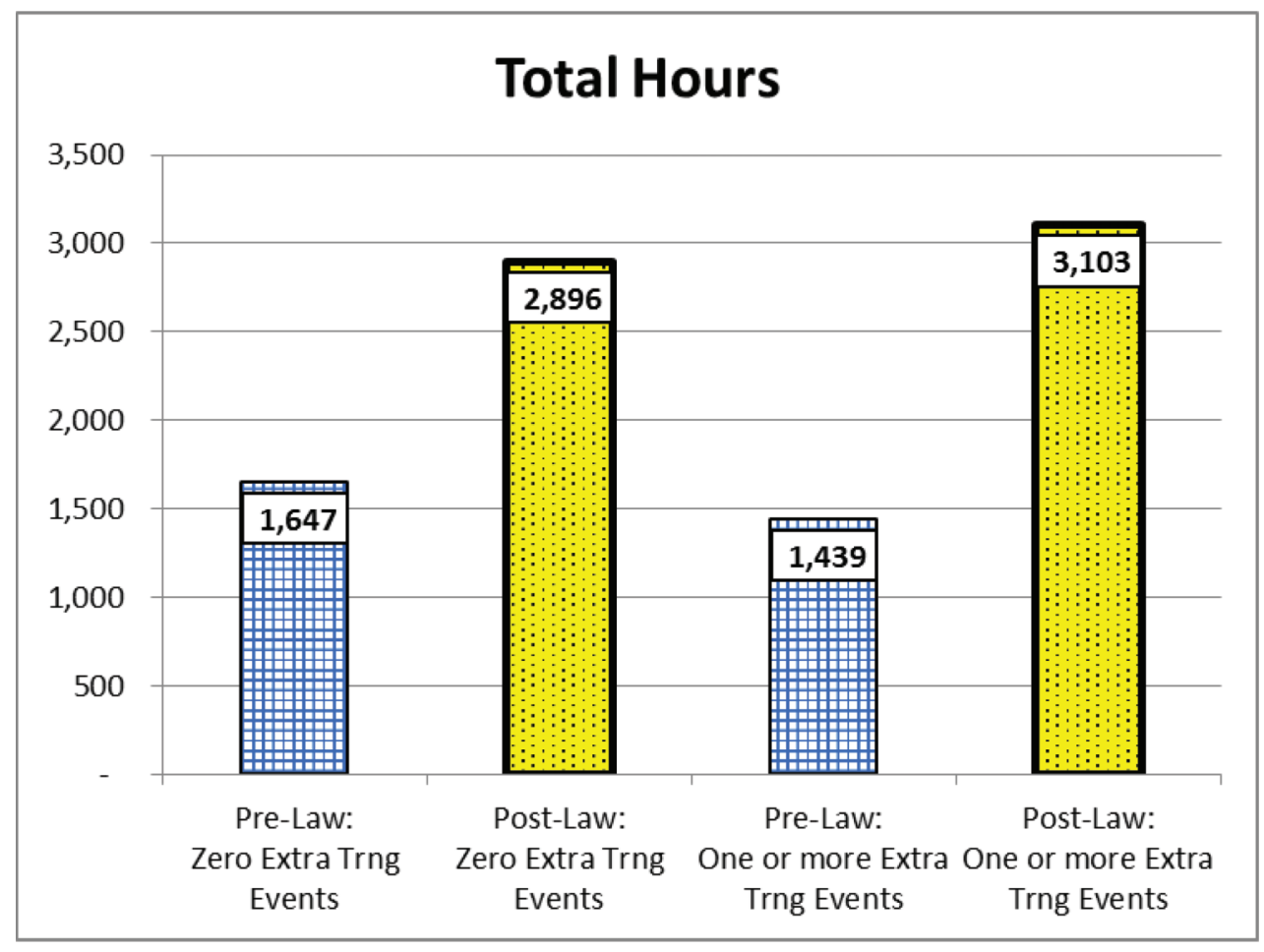

Figure 11. Total Flight Hours with Pre-Law/Post-Law Extra Training Events. 


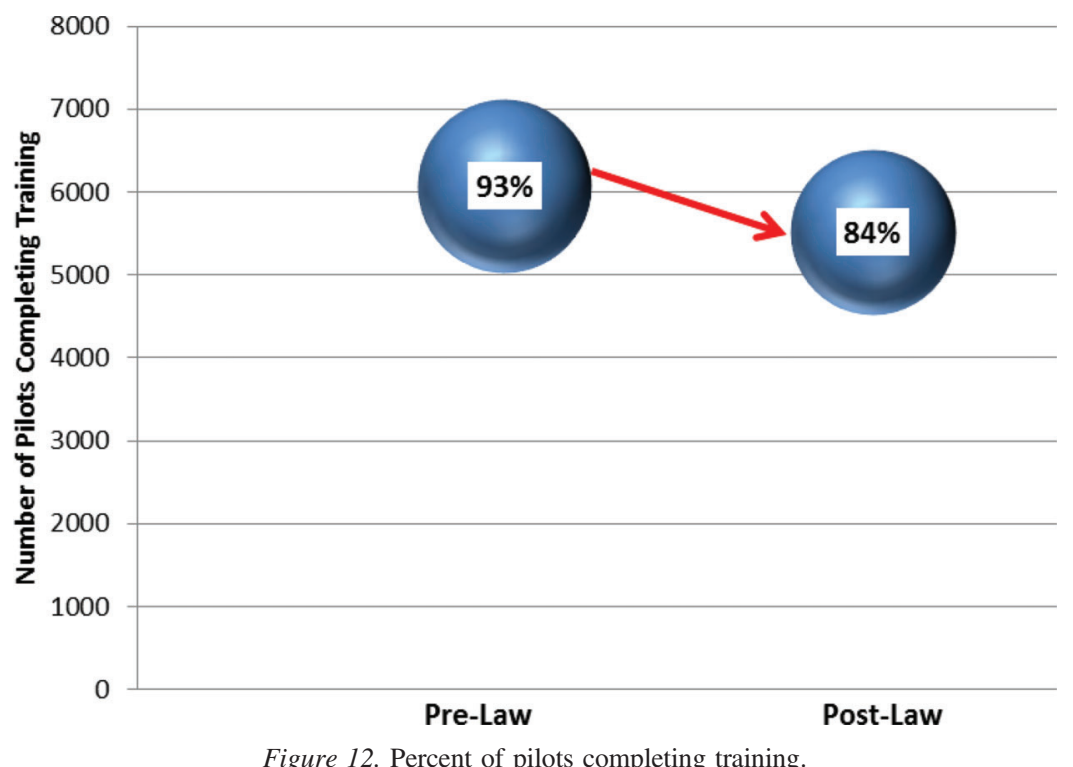

variables. Inclusion of these dichotomous variables improved the discriminating function of the equation. The equation more accurately predicted membership in the Completions group than in the Non-Completions. For Completions, $83 \%$ of the cases were correctly predicted; for NonCompletions, $56 \%$ of the cases were correctly predicted. The discriminant analysis function incorrectly classified (misclassified) Completions for $17 \%$ of the cases; for NonCompletions, $44 \%$ of the cases were incorrectly classified. One discriminant function was created with an eigenvalue of .063, canonical correlation of .244, Wilks' $\lambda=.940, p<$ .001 . The computed discriminant function is displayed in Equation 1. The strength of the coefficient for Extra Training Events provides confidence that the Extra Training variable is the principal factor for Completions.

$$
\begin{gathered}
\text { Completions }=-.125(\text { AABI Flight Degree }) \\
-.162 \text { (Aviation Degree })-.164(\text { CFI Certificate }) \\
+.209 \text { (Total Flight Hours }) \\
-.853 \text { (Extra Training Events })
\end{gathered}
$$

Pre-Law/Post-Law Completions With Independent Variables

A new variable was created that combined the variables Pre-Law/Post-Law and Completions. The new variable has four categories: Pre-Law-Non-Completion; Post-LawNon-Completion; Pre-Law-Completion; and Post-LawCompletion. The following sections describe how the independent variables significantly influenced this new combined outcome variable, Pre-Law/Post-Law Completions.

College Degree With Pre-Law/Post-Law Completions

Using the chi-square test of significance, College Degree with Pre-Law/Post-Law Completions was statistically significant: $N=11,473, \chi^{2}(6)=82.349, p<.001$; Cramer's $V=.060, p<.001$. Bachelor's Degree increased its positive effect on non-completions between Pre-Law and Post-Law-yielding fewer Post-Law pilots with noncompletions. No Degree and Associate Degree increased their negative effect on non-completions between Pre-Law and Post-Law-yielding more Post-Law pilots with noncompletions. Associate Degree increased its negative effect on completions between Pre-Law and Post-Law-yielding fewer Post-Law pilots with completions. The following cells had significant contributions to the chi-square, as displayed in Figure 13.

- For Post-Law-Non-Completions: Pilots with No Degree had significantly more Non-Completions than expected: Observed $=221$ versus Expected $=155$; Chi-square contribution $=34 \%$.

- For Post-Law-Non-Completions: Pilots with an Associate Degree had significantly more Non-Completions than expected: Observed $=127$ versus Expected $=84.8$; Chi-square contribution $=26 \%$.

- For Post-Law-Non-Completions: Pilots with a Bachelor's Degree had significantly fewer NonCompletions than expected: Observed $=529$ versus Expected $=637.1$; Chi-square contribution $=22 \%$ [positive outcome].

- For Post-Law-Completions: Pilots with an Associate Degree had significantly fewer Completions than expected: Observed $=387$ versus Expected $=437.9$; Chi-square contribution $=7 \%$.

Aviation Degree With Pre-Law/Post-Law Completions

Using the chi-square test of significance, Aviation Degree with Pre-Law/Post-Law Completions was statistically significant: $N=9,492, \chi^{2}(3)=301.753, p<.001$; 


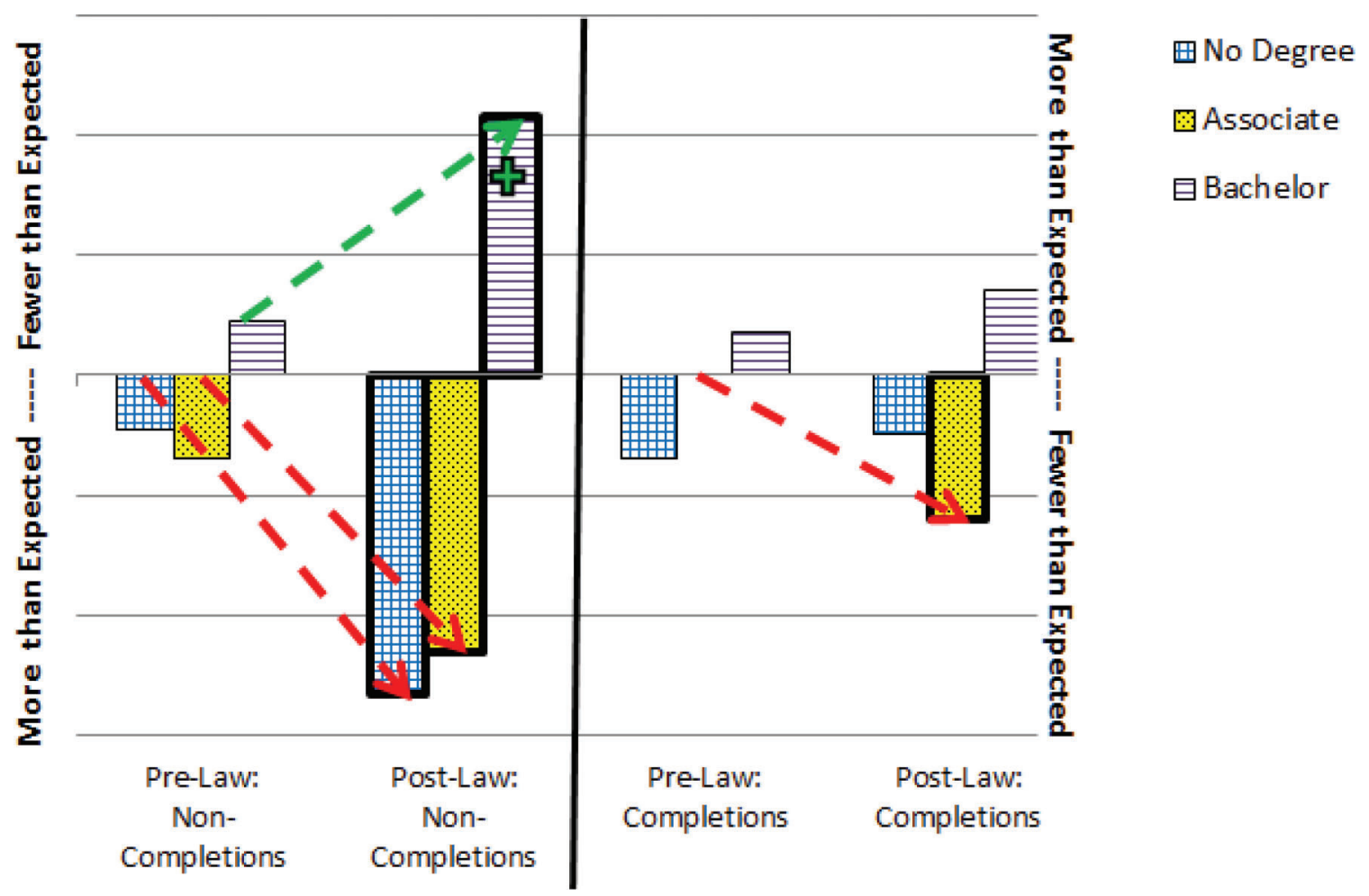

Figure 13. College Degree with Pre-Law/Post-Law Completions.

Cramer's $V=.178, p<.001$. Aviation Degree increased its positive effect on non-completions between Pre-Law and Post-Law-yielding fewer Post-Law pilots with noncompletions. Non-Aviation Degree increased its negative effect on non-completions between Pre-Law and Post-Law-yielding more Post-Law pilots with noncompletions. Aviation Degree lost its positive effect on completions between Pre-Law and Post-Law-yielding fewer Post-Law pilots with completions. Non-Aviation Degree increased its positive effect on completions between Pre-Law and Post-Law-yielding more PostLaw pilots with completions. The following cells were statistically significant in their contribution to the chisquare, as displayed in Figure 14.

- For Post-Law-Non-Completions: Pilots with a Non-Aviation Degree had significantly more NonCompletions than expected: Observed $=534$ versus Expected $=372.9$, Chi-square contribution $=23 \%$.

- For Post-Law-Non-Completions: Pilots with an Aviation Degree had significantly fewer NonCompletions than expected: Observed $=338$ versus Expected $=499.1$, Chi-square contribution $=17 \%$ [positive outcome].

- For Pre-Law-Completions: Pilots with a NonAviation Degree had significantly fewer Completions than expected: Observed $=1,293$ versus Expected $=1,661.3$, Chi-square contribution $=$ $27 \%$.
- For Pre-Law-Completions: Pilots with an Aviation Degree had significantly more Completions than expected: Observed $=2,592$ versus Expected $=2,223.7$, Chi-square contribution $=20 \%$ [positive outcome].

- For Post-Law-Completions: Pilots with a Non-Aviation Degree had significantly more Completions than expected: Observed $=2,089$ versus Expected $=1,899.9$, Chi-square contribution $=6 \%$ [positive outcome].

- For Post-Law-Completions: Pilots with an Aviation Degree had significantly fewer Completions than expected: Observed $=2,354$ versus Expected $=$ 2,543.1, Chi-square contribution $=5 \%$.

\section{AABI Flight Degree With Pre-Law/Post-Law Completions}

Using the chi-square test of significance, AABI Flight Degree with Pre-Law/Post-Law Completions was statistically significant: $N=9,691, \chi^{2}(3)=184.064, p<.001$; Cramer's $V=.138, p<.001$. AABI Flight Degree increased its positive effect on non-completions between Pre-Law and Post-Law-yielding fewer Post-Law pilots with noncompletions. No-AABI Flight Degree increased its negative effect on non-completions between Pre-Law and Post-Lawyielding more Post-Law pilots with non-completions. AABI Flight Degree lost its positive effect on completions between Pre-Law and Post-Law-yielding fewer PostLaw pilots with completions. No-AABI Flight Degree increased its positive effect on completions between 


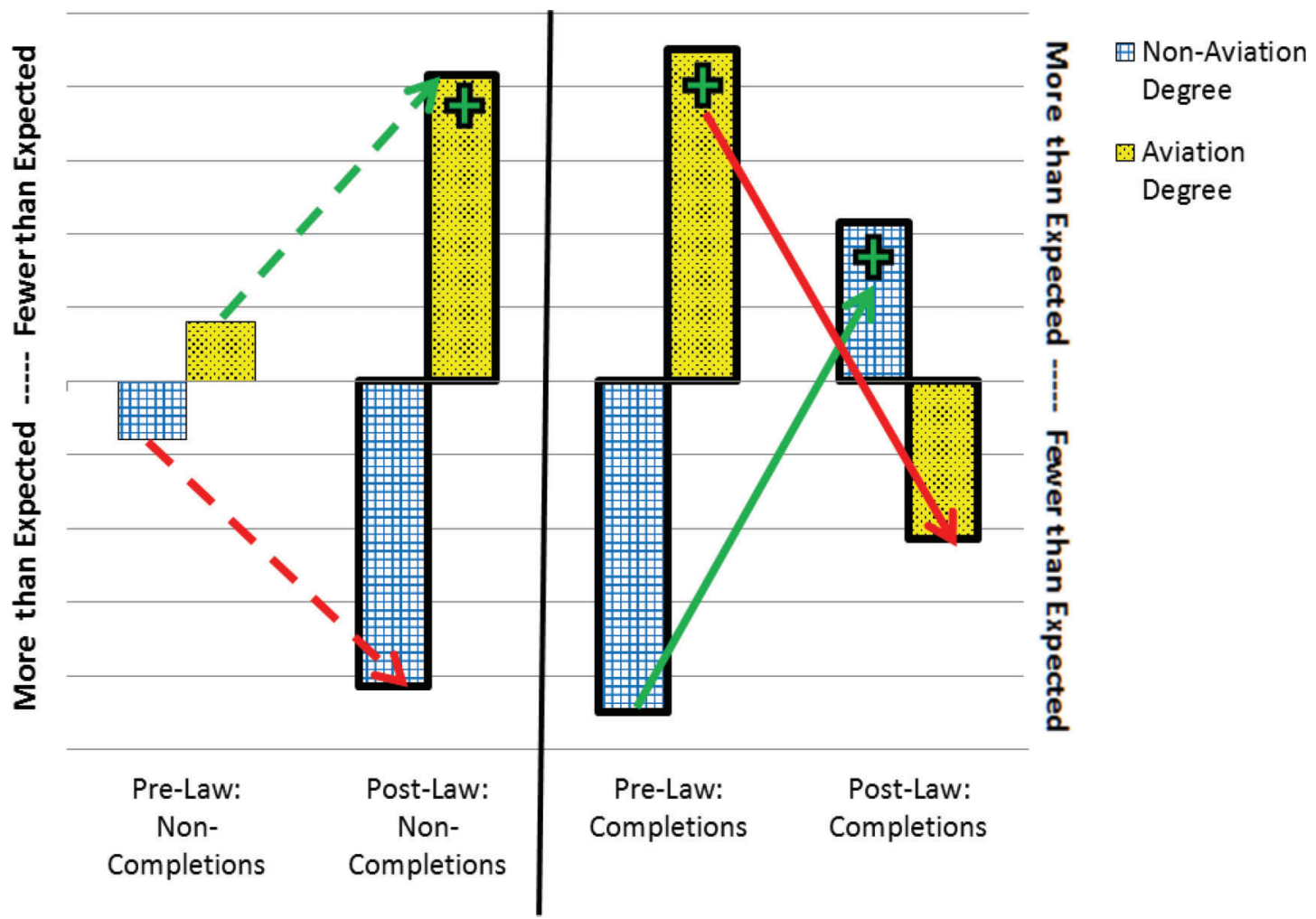

Figure 14. Aviation Degree with Pre-Law/Post-Law Completions.

Pre-Law and Post-Law-yielding more Post-Law pilots with completions. The following cells were statistically significant in their contribution to the chi-square, as displayed in Figure 15.

- For Pre-Law-Non-Completions: Pilots with an AABI Flight Degree had significantly fewer NonCompletions than expected, Observed $=54$ versus Expected $=79.1$, Chi-square contribution $=4 \%$ [positive outcome].

- For Post-Law-Non-Completions: Pilots with a NonAABI Flight Degree had significantly more NonCompletions than expected, Observed $=786$ versus Expected $=660.6$, Chi-square contribution $=13 \%$.

- For Post-Law-Non-Completions: Pilots with an AABI Flight Degree had significantly fewer NonCompletions than expected, Observed $=120$ versus Expected $=245.5$, Chi-square contribution $=35 \%$ [positive outcome].

- For Pre-Law-Completions: Pilots with a Non-AABI Flight Degree had significantly fewer Completions than expected, Observed $=2,591$ versus Expected $=$ 2,832.7, Chi-square contribution $=11 \%$.

- For Pre-Law-Completions: Pilots with an AABI Flight Degree had significantly more Completions than expected, Observed $=1,294$ versus Expected $=$ 1,052.3, Chi-square contribution $=30 \%$ [positive outcome].
- For Post-Law-Completions: Pilots with an $A A B I$ Flight Degree had significantly fewer Completions than expected, Observed $=1,157$ versus Expected $=$ $1,248.2$, Chi-square contribution $=4 \%$.

Previous Experience With Pre-Law/Post-Law Completions

Using the chi-square test of significance, Previous Experience with Pre-Law/Post-Law Completions was statistically significant: $N=9,882, \chi^{2}(6)=75.142, p<$ .001 ; Cramer's $V=.062, p<.001$. Previous Airline and Corporate experience increased their negative effect on non-completions between Pre-Law and Post-Lawyielding more Post-Law pilots with non-completions. Previous Flight Instructor experience increased its positive effect on non-completions between Pre-Law and Post-Law-yielding fewer Post-Law pilots with noncompletions. Previous Corporate experience increased its positive effect on completions between Pre-Law and Post-Law-yielding more Post-Law pilots with completions. Previous Flight Instructor experience lost its positive effect on completions between Pre-Law and Post-Law-yielding fewer Post-Law pilots with completions. The following cells were statistically significant in their contribution to the chi-square, as displayed in Figure 16.

- For Post-Law-Non-Completions: Pilots whose primary Previous Employment was with an Airline had 


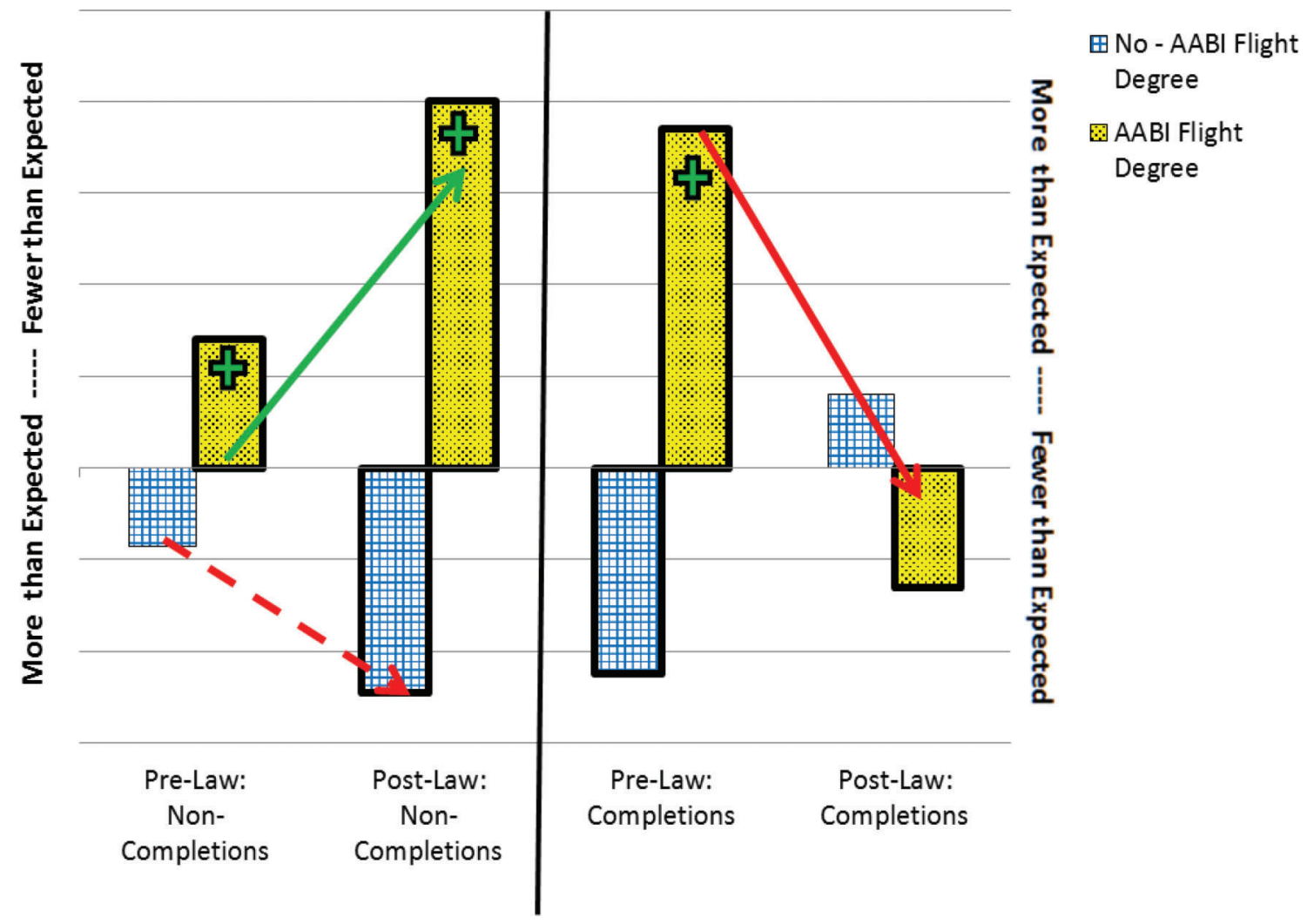

Figure 15. AABI Flight Degree with Pre-Law/Post-Law Completions.

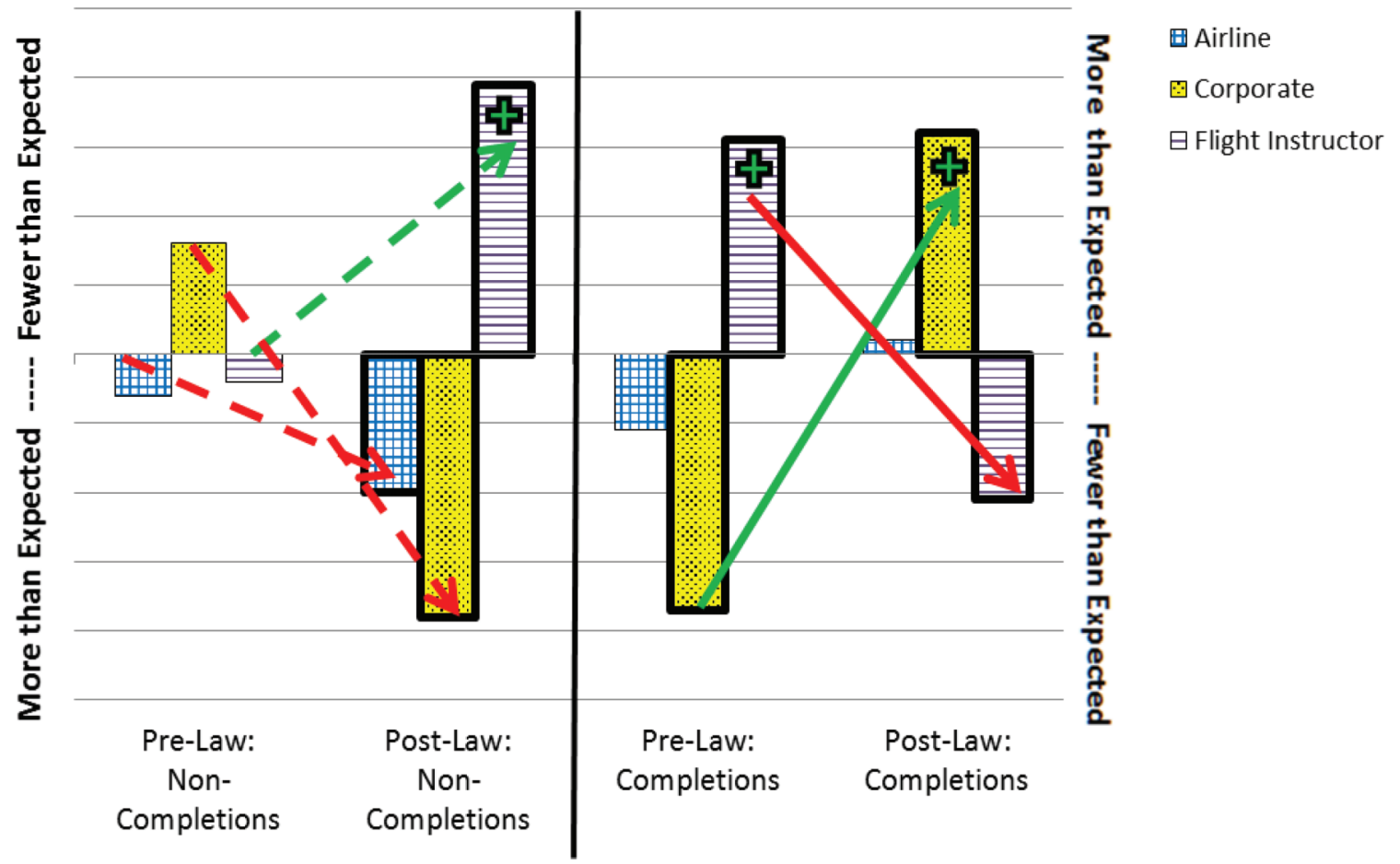

Figure 16. Previous Experience with Pre-Law/Post-Law Completions.

significantly more Non-Completions than expected, Observed $=263$ versus Expected $=232.8$, Chisquare contribution $=5 \%$.
- For Post-Law-Non-Completions: Pilots whose primary Previous Employment was in Corporate aviation had significantly more Non-Completions than 
expected, Observed $=162$ versus Expected $=120.4$, Chi-square contribution $=19 \%$.

- For Pre-Law-Completions: Pilots whose primary Previous Employment was in Corporate aviation had significantly fewer Completions than expected, Observed $=779$ versus Expected $=888.5$, Chisquare contribution $=18 \%$.

- For Post-Law-Completions: Pilots whose primary Previous Employment was in Corporate aviation had significantly more Completions than expected, Observed $=709$ versus Expected $=628.5$, Chi-square contribution $=14 \%$ [positive outcome].

- For Post-Law-Non-Completions: Pilots whose primary Previous Employment was Flight Instructor had significantly fewer Non-Completions than expected, Observed $=276$ versus Expected $=347.8$, Chisquare contribution $=20 \%$ [positive outcome].

- For Pre-Law-Completions: Pilots whose primary Previous Employment was Flight Instructor had significantly more Completions than expected, Observed $=2,722$ versus Expected $=2567.1$, Chi-square contribution $=12 \%$ [positive outcome].

- For Post-Law-Completions: Pilots whose primary Previous Employment was Flight Instructor had significantly fewer Completions than expected, Observed $=1,727$ versus Expected $=1,815.9$, Chi-square contribution $=6 \%$.

CFI Certificate With Pre-Law/Post-Law Completions

Using the chi-square test of significance, CFI Certificate with Pre-Law/Post-Law Completions was statistically significant: $N=11,584, \chi^{2}(3)=108.414, p<.001$; Cramer's $V=.097, p<.001$. Having a CFI Certificate increased its positive effect on non-completions between Pre-Law and Post-Law-yielding fewer Post-Law pilots with non-completions. Not having a CFI Certificate increased its negative effect on non-completions between Pre-Law and Post-Law-yielding more Post-Law pilots with non-completions. Having a CFI Certificate decreased its positive effect on completions between Pre-Law and Post-Law-yielding fewer Post-Law pilots with completions. The effects of not having a CFI Certificate were eliminated for Post-Law completions. The following cells were statistically significant in their contribution to the chisquare, as displayed in Figure 17.

- For Pre-Law-Non-Completions: Pilots with No CFI Certificate had significantly more Non-Completions than expected, Observed $=105$ versus Expected $=$ 78.2, Chi-square contribution $=8 \%$.

- For Post-Law-Non-Completions: Pilots with No CFI Certificate had significantly more Non-Completions than expected, Observed $=283$ versus Expected $=$ 177.9, Chi-square contribution $=57 \%$.

- For Pre-Law-Completions: Pilots with No CFI Certificate had significantly fewer Completions than expected, Observed $=981$ versus Expected = 1,113.9, Chi-square contribution $=15 \%$.

- For Post-Law-Non-Completions: Pilots with a CFI Certi4ficate had significantly fewer Non-Completions than expected, Observed $=623$ versus Expected $=728.1$, Chi-square contribution $=14 \%$ [positive outcome].

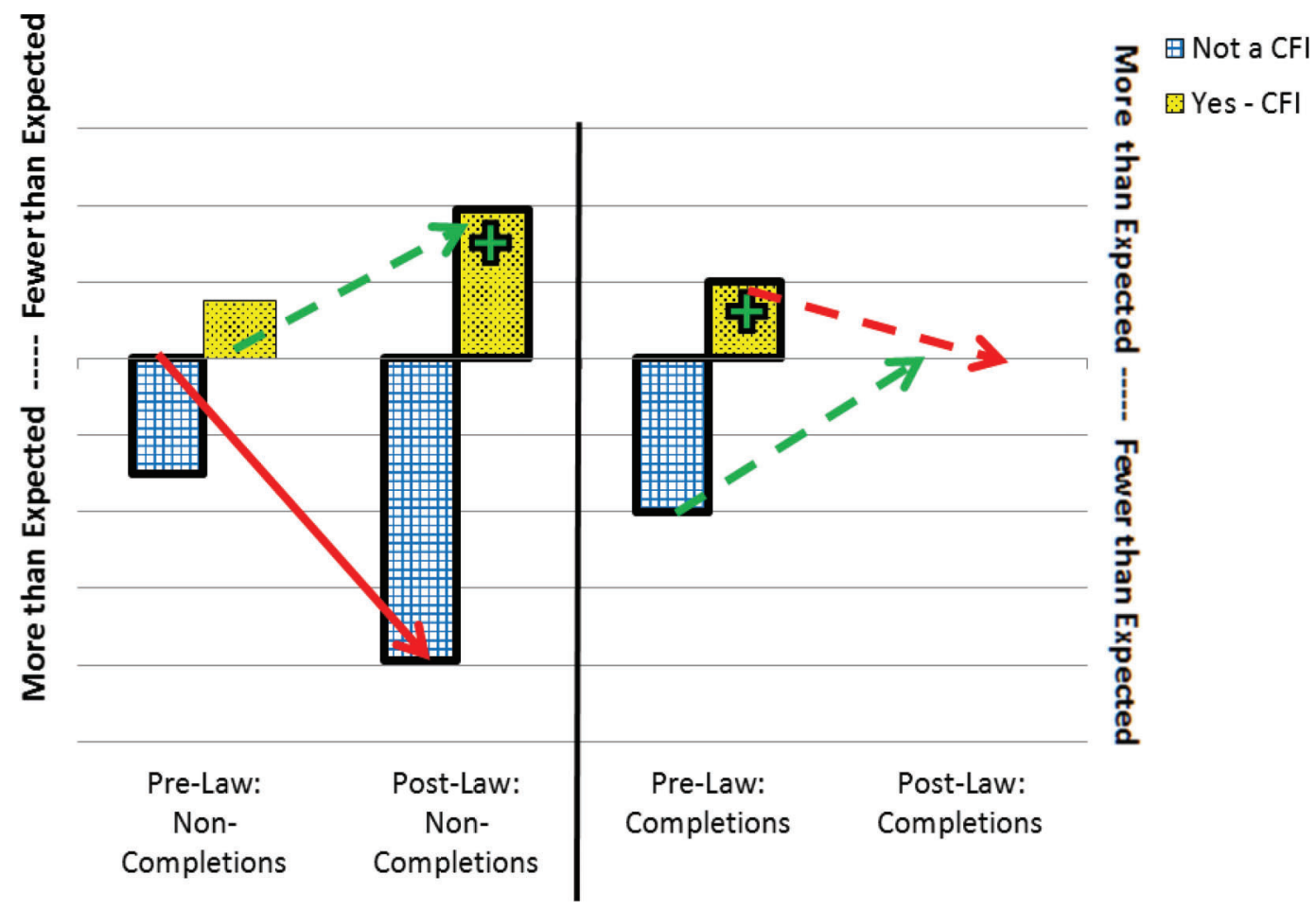

Figure 17. CFI Certificate with Pre-Law/Post-Law Completions. 


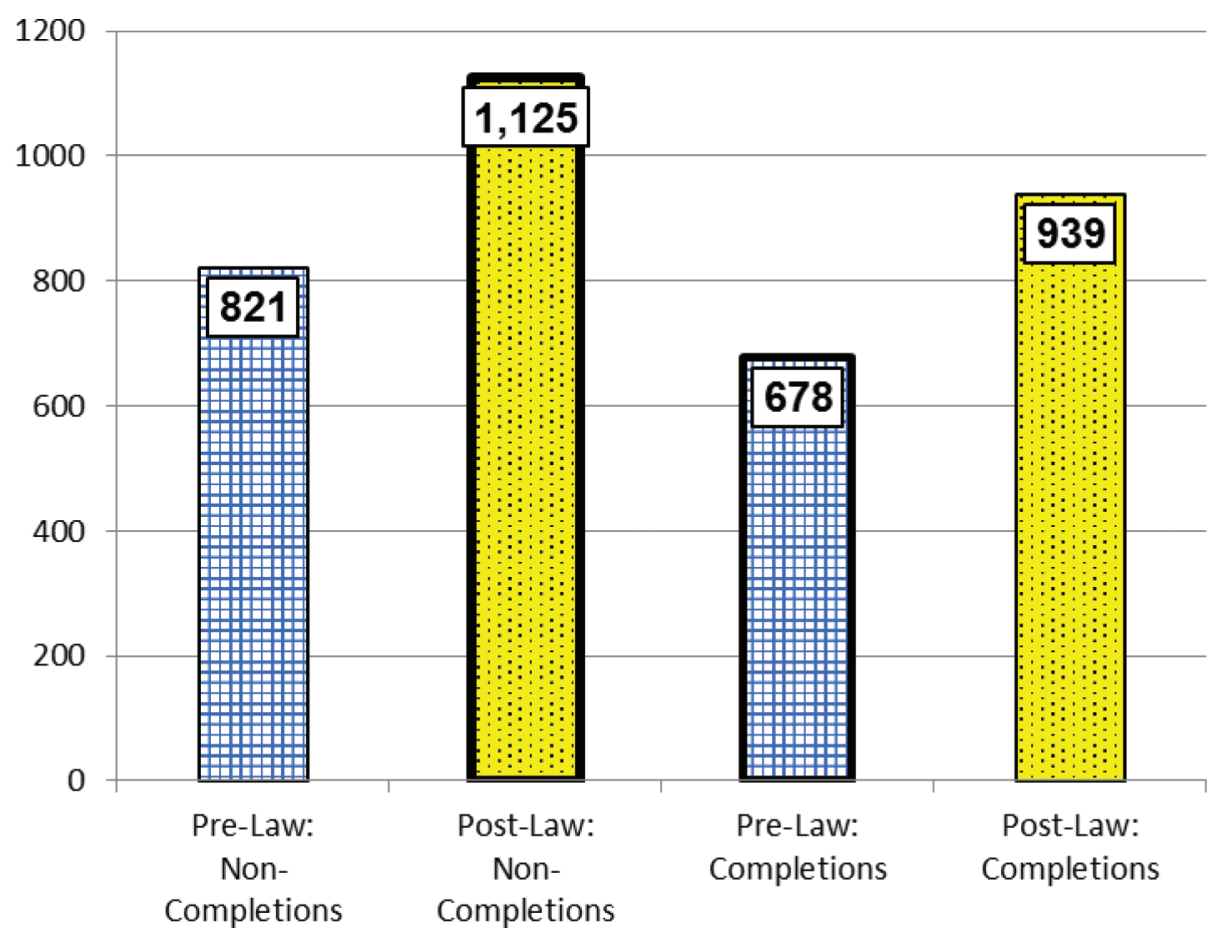

Figure 18. Dual Given with Pre-Law/Post-Law Completions.

- For Pre-Law-Completions: Pilots with a CFI Certificate had significantly more Completions than expected, Observed $=4,691$ versus Expected $=4,558.1$, Chi-square contribution $=4 \%$ [positive outcome].

\section{Dual Given and Pre-Law/Post-Law Completions}

Using an ANOVA, the means for Dual Given with the factor as Pre-Law/Post-Law Completions were statistically significant: $N=5,583, F(3,5,579)=89.95, p<.001$; a significant difference exists among the four categories. The additional Dual Given hours under Post-Law were less beneficial to regional airline training; in fact, the completers have fewer Dual Given hours than non-completers. The Levene test for the homogeneity of variance was significant, $W(3,5,579)=71.68, p<.001$; therefore, the GamesHowell post hoc tests for unequal variances were used. In the ANOVA post hoc analysis, there were two important results (see Figure 18).

- The Dual Given mean for the Post-Law NonCompletions (mean $=1,125$ hours) was significantly higher than the mean for Pre-Law Non-Completions (mean $=821$ hours). Dual Given in the Post-Law Non-Completions group had significantly more Dual Given hours than any of the other groups.

- The Dual Given mean for the Pre-Law Completions (mean $=678$ hours) was significantly lower than the Dual Given mean for the Post-Law Completions (mean $=939$ hours). This result is not unexpected; pilots used flight instructing hours to increase their total flight hours to qualify under the FOQ Rule.
Total Flight Hours and Pre-Law/Post-Law Completions

Using an ANOVA, the means for Total Flight Hours with the factor as Pre-Law/Post-Law Completions were statistically significant: $N=11,398, F(3,11,394)=$ $454.31, p<.001$; a significant difference exists among the four categories. The Levene test for the homogeneity of variance was significant, $W(3,11,394)=315.88, p<.001$; therefore, the Games-Howell post hoc tests for unequal variances were used. The higher Total Flight Hours, required by PL 111-216, did not yield fewer noncompletions for Post-Law pilots. As the number of Total Flight Hours increases, so do the proportion of noncompletions; the result is a significant positive correlation (Spearman's rho $=.228, p<.001)$. In the ANOVA post hoc analysis, there were two important results (see Figure 19).

- The average Total Flight Hours for the Pre-Law NonCompletions (mean $=2,012$ hours) was significantly lower than the average Total Flight Hours for PostLaw Non-Completions (mean $=3,996$ hours).

- The average Total Flight Hours for the Pre-Law Completions (mean $=1,567$ hours) was significantly lower than the average Total Flight Hours for the Post-Law Completions (mean $=2,894$ ).

\section{Pre-Law/Post-Law IOE z-Score With Background Variables}

For all of Pilot Source Study 2015, IOE z-Scores greater than one standard deviation (+1 SD) were considered Extra 


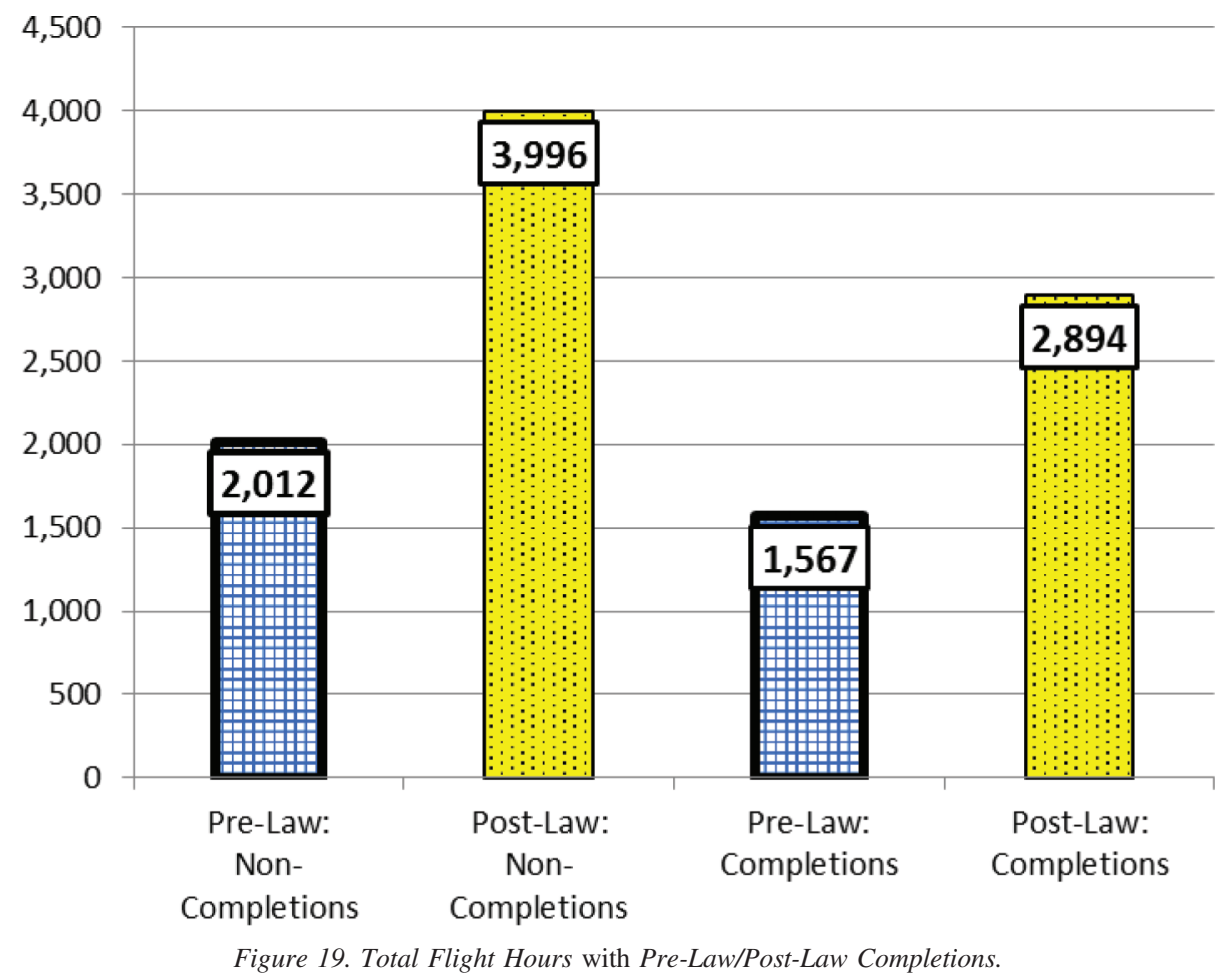

IOE. The IOE z-Scores were binned into a dichotomous variable: Normal $\mathrm{IOE}=+1 \mathrm{SD}$ or less; Extra $\mathrm{IOE}=$ more than +1 SD. A new variable was created that combined the Pre-Law/Post-Law variables with the IOE z-Score dichotomous variable to create a variable that had four options: Pre-Law and Normal IOE, Post-Law and Normal IOE, Pre-Law and Extra IOE, and Post-Law and Extra IOE. Two background variables significantly influenced this new combined outcome variable, Pre-Law/Post-Law IOE $z$-Score, in the following ways.

AABI Flight Degree and Pre-Law/Post-Law IOE z-Score

Using the chi-square test of significance, AABI Flight Degree with Pre-Law/Post-Law IOE z-Score was statistically significant: $N=6,693, \chi^{2}(3)=51.668, p<.001$; Cramer's $V=.088, p<.001$. Having an AABI Flight Degree lost some of its positive effect on Normal IOE between Pre-Law and Post-Law-yielding fewer Post-Law pilots with Normal IOE. Not having an AABI Flight Degree decreased its negative effect on Normal IOE between PreLaw and Post-Law-yielding more Post-Law pilots with Normal IOE. Having an AABI Flight Degree increased its positive effect on Extra IOE between Pre-Law and PostLaw-yielding fewer Post-Law pilots with Extra IOE. Not having an AABI Flight Degree increased its negative effect on Extra IOE between Pre-Law and Post-Law-yielding more Post-Law pilots with Extra IOE. The following cells were statistically significant in their contribution to the chisquare, as displayed in Figure 20.

- For Pre-Law-Normal IOE: Pilots who have a Non$A A B I$ Flight Degree had significantly fewer Normal
IOE scores than expected, Observed $=1,253$ versus Expected $=1352.1$, Chi-square contribution $=14 \%$.

- For Pre-Law-Normal IOE: Pilots who have an AABI Flight Degree had significantly more Normal IOE scores than expected, Observed $=601$ versus Expected $=501.9$, Chi-square contribution $=38 \%$ [positive outcome].

- For Post-Law-Extra IOE: Pilots who have a NonAABI Flight Degree had significantly more Extra IOE scores than expected, Observed $=458$ versus Expected $=411.3$, Chi-square contribution $=10 \%$.

- For Post-Law-Extra IOE: Pilots who have an AABI Flight Degree had significantly fewer Extra IOE scores than expected, Observed $=106$ versus Expected $=152.7$, Chi-square contribution $=28 \%$ [positive outcome].

Total Flight Hours and Pre-Law/Post-Law IOE z-Score

Using an ANOVA, Total Flight Hours with Pre-Law/ Post-Law IOE z-Score were statistically significant: $N=$ $7,429, F(3,7,425)=144.73, p<.001$. The Levene test for the homogeneity of variance was significant, $W(3$, $7,425)=131.88, p<.001$; therefore, the Games-Howell post hoc tests for unequal variances were used. In the ANOVA post hoc analysis, the Total Flight Hours for each category was significantly different from the other categories. For both the Pre-Law and Post-Law pilots, those pilots requiring Extra IOE have fewer flight hours than pilots who have Normal IOE. The increase in Total Flight Hours is approximately 1,000 flight hours between 


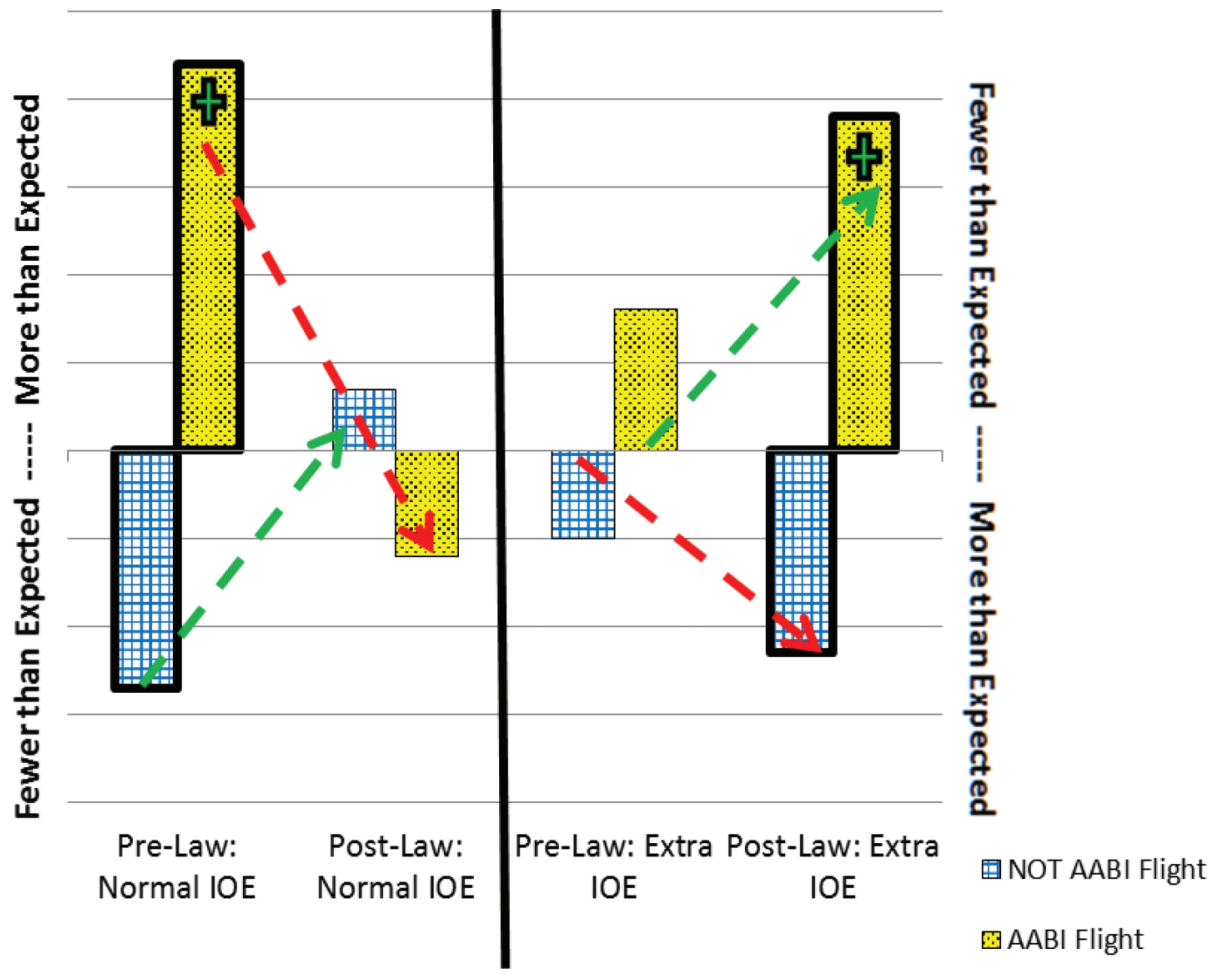

Figure 20. AABI Flight with Pre-Law/Post-Law IOE z-Score.

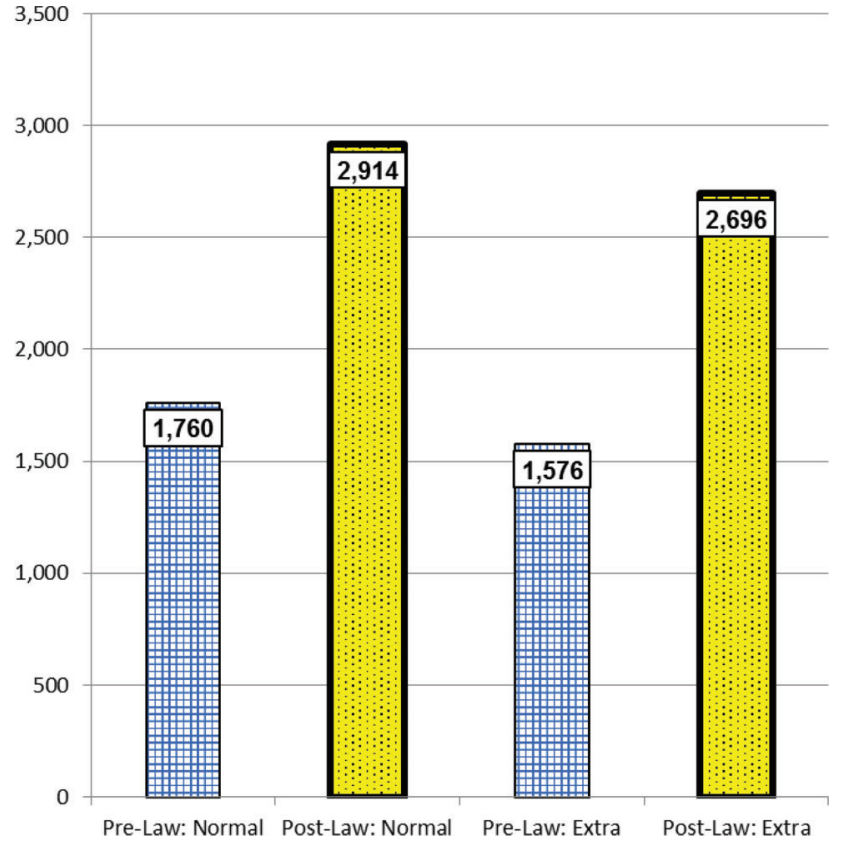

Figure 21. Total Flight Hours with Pre-Law/Post-Law IOE z-Score.

the Pre-Law average flight hours and the Post-Law average flight hours (see Figure 21).

\section{Discussion and Recommendations}

The purpose of the Pilot Source Study 2015 was to determine the impact of PL 111-216 and the subsequent
FOQ Rule on pilot hiring and training at U.S. regional airlines. The results of the research have been presented in three articles, concluding with this report. The Appendix is a summary of the results of this report that determined, for Part 121 regional airlines, whether the success of the PostLaw pilots was different from the success of the Pre-Law pilots, considering the differences in their background characteristics. In the Appendix, the summary of differences between Pre-Law/Post-Law background variables (discussed in article 1) highlights the decrease in background characteristics, except in the Post-Law data, there are more Military and Corporate Pilots and, of course, more Dual Given hours and more Total Flight Hours, as a consequence of PL 111-216. Concerning the differences in outcomes at Part 121 regional airlines between Pre-Law/ Post-Law, Extra Training significantly increased, Completions significantly decreased, IOE z-Scores did not significantly change, and there were insufficient data to determine a change in Recurrent Training.

Multiple variables showed there were statistically significant differences between pilots hired before August 1, 2013 and those hired after that date. Pilots hired after PL 111-216 went into effect had fewer AABI-Accredited Flight degrees, fewer aviation degrees, and included more military-trained pilots. More pilots in the Post-Law group worked as corporate pilots and fewer Post-Law pilots had their CFI certificate and worked as a flight instructor prior to joining the airline. An equivalent number of pilots worked as airline pilots before and after the law went into effect. The only background variable that gave positive outcomes 
in fewer Non-Completions, Less Extra Training, and Less Extra IOE was graduating from an AABI-Accredited Flight program.

Quality of education and quality of flight training have more of an impact than total flight hours. All three Pilot Source Studies have shown that flight hours are not a reliable predictor of performance by pilots. This research suggests that bachelor's degree graduates of AABI-Accredited Flight programs are more likely to be successful in air carrier new-hire training programs and in airline qualifications, especially when they transition from college to airline training without spending significant time away from the profession. Based on the results of this study, it would be beneficial to revisit how the FAA views structured training programs such as AABI-Accredited Flight programs that follow a structured curriculum according to industry/educator collaborated criteria (AABI, 2016). This study demonstrated that graduates from AABI-Accredited Flight programs perform as well as military-trained pilots and should be granted the same FAA regulatory relief as the 750-hour military reduction. If there is indeed a pilot shortage at the regional airline level, a reduced flight hour requirement for graduates from an AABI-Accredited Flight program would permit airlines to hire well-trained pilots earlier in their careers when they are statistically capable of completing rigorous airline training programs and requiring less extra training. Airlines seeking to hire new pilots should place value on military pilots and graduates from an AABI-Accredited Flight program. Based on the results of this research, pilots graduating from an AABI-Accredited Flight program had an increased likelihood of success in initial training and line qualification.

Extra training events were used as an indication of pilot competency and readiness for the rigors of Part 121 training. The average increased from .5 extra training events per Pre-Law pilot to 1.2 extra training events per Post-Law pilot. On average, pilots required more extra training after the enactment of PL 111-216. Out of the 6,608 Pre-Law pilots, 1,493 (22.59\%) Pre-Law pilots had extra training events ranging from one to 38 . Out of the 5,118 Post-Law pilots, 1,835 (33.25\%) Post-Law pilots had extra training events ranging from one to 45. To quantify, the Pre-Law pilots had 3,182 extra training events and the Post-Law pilots had 6,147 extra training events. The Post-Law pilots, with extensively higher average total flight hours, required 2,965 more extra training events than the Pre-Law pilots. The magnitude of this difference between Pre-Law and Post-Law extra training events should be even larger because Post-Law extra training events are underrepresented. When some regional airlines extended their PostLaw training footprint for all pilots, some extra training was no longer identified as extra training in the extended training footprint.
The coefficient for Extra Training Events in the discriminant function for Completions (Equation 1) is evidence that Extra Training is the principal factor for Completions. To determine if there was a difference in the effect of Extra Training between Pre-Law and Post-Law Completions, an ANOVA was calculated between the means for Extra Training Events with the factor as Pre-Law/Post-Law Completions. The means are statistically significant: $N=11,055$, $F(3,11,051)=290.19, p<.001$; indicating a significant difference exists among the four categories. Pilots who terminated (Pre-Law or Post-Law) had a higher mean for Extra Training than pilots who successfully completed training (Pre-Law or Post-Law). Pilots who successfully completed training required less Extra Training (see Figure 22).

Quantifying the actual cost of non-completions is important to the airlines and to stakeholders addressing pilot training issues. The researchers requested participating airlines to provide specific training costs in order to estimate the cost of non-completions.

Using the average of seven U.S. regional airlines who shared training costs with the researchers, each pilot was paid $\$ 43,082$ per year (or $\$ 118$ per day for each pilot) for salary and benefits. The average cost of accommodations during training (per diem, hotels, etc.) was $\$ 106$ per day for each pilot. From the airline data, the prorated airline cost (instructors, simulators, staff, overhead, etc.) is $\$ 20,345$ per pilot.

The proportion of non-completer pilots in the Post-Law dataset that exceeds the proportion of non-completer pilots in the Pre-Law dataset is $9.87 \%$ (see Figure 12), or 544 additional pilots who did not complete training. From the cost survey, the average non-completer pilot terminates in 53 training days (2.65 months) - yielding a total cost of $\$ 38,464$ for each non-completer pilot. The total cost to Regional Airlines for the 544 additional Post-Law non-completer pilots is $\$ 20,924,516$; unfortunately, the regional airlines received zero return on their investment from these additional pilots who did not complete training.

Additional studies are needed to continue the research presented in the Pilot Source Studies. The authors recommend a longitudinal study designed to determine the success of the Post-Law new-hire pilot group. Additionally, this study's methodology could be expanded to business aviation, major airlines, and other aviation-based services, such as maintenance and air traffic control, to determine whether the background of the employees (pilots, maintenance technicians, or air traffic controllers) makes a difference in their training and on-the-job performance. Lastly, a follow-up study to the Pilot Source Study 2015 should be commissioned to determine the impacts that airline pipeline and gateway programs have on hiring and retention. 


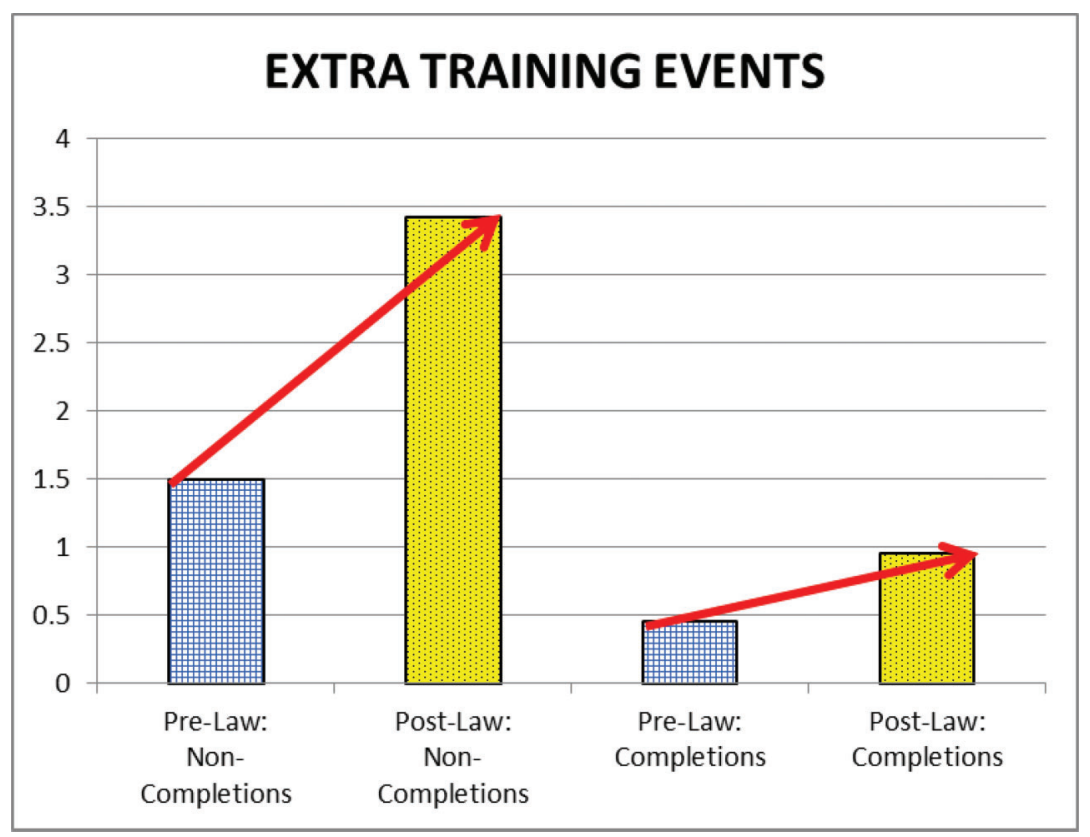

Figure 22. Extra Training Events with Pre-Law/Post-Law Completions.

\section{Conclusions}

The original "Pilot Source Study 2010" was commissioned in February of 2010 in order to respond to a question posed by the FAA in an Advanced Notice of Proposed Rulemaking (ANPRM) (FAA, 2010, February 8). The FAA specifically asked the question "Do graduates of accredited aviation programs perform better in training?" In early 2010, there were no data compiled at the time to answer that very specific question. A group of researchers set out to mine the needed data from a convenience sample of regional airlines, and then analyze the results collectively (Smith et al., 2010). Since February of 2010, over 14,000 individual pilot records have been collected, coded, and analyzed through the three different Pilot Source Studies (2010, 2012, and 2015). In all three studies, pilots who graduated from AABI-Accredited Flight programs performed significantly better in initial training than pilots who did not graduate from AABI-Accredited Flight programs. This compilation and analysis of a large amount of data allows for a definitive answer to the question posed by the FAA - yes, graduates of AABI-Accredited Flight programs do perform better in training.

The other consistent finding in the Pilot Source Studies (2010, 2012, and 2015) relates to the impact that total flight hours has on performance in initial pilot training. All three studies found that the groups of pilots who performed significantly better in training had fewer than 1,500 total flight hours. These results consistently affirm that the number of flight hours is not associated with successful performance in regional airline pilot training. The conventional conclusion is that the quality of training should be used as an indicator of success. Though the Pilot Source
Study 2015 did not directly investigate training quality, the data show that the U.S. military and AABI-Accredited Flight programs produce pilots who are more successful. The U.S. military and AABI-Accredited Flight programs have four features that exemplify quality programs: (a) they are guided by criteria that exceed FAA certificate requirements; (b) they operate in a highly structured and supervised environment; (c) they are routinely evaluated by an external agency; and (d) they consistently require disciplined flying. The authors recommend a follow-on study to determine the quality of all pilot training programs that includes at least these four constructs: criteria or competencies, structured training, external evaluations, and disciplined flying.

Before PL 111-216, regional airlines could establish distinctive criteria for hiring pilots and could train them to their standards for safe and proficient operations. Contrary to intent, PL 111-216 did not create highly successful regional airline pilots; instead, it eliminated a group of pilots from the pilot pool who had performed well in the earlier Pilot Source Studies 2010 and 2012. The Pilot Source Study 2015 supports the earlier results_-pilots with fewer than 1,500 total flight hours were more successful than their counterparts with more total flight hours. Ultimately, the airline bears responsibility for the pilots they hire and train; this study provides empirical measures to help airlines determine candidates who are likely to succeed in the current airline training model. While ab initio and gateway programs might be successful, a vital component of the whole person is lost in a narrowly focused training program. The Pilot Source Study 2015 demonstrates that the most successful regional airline candidate is one who advanced to a regional airline within four years after graduation; had an R-ATP with fewer than 


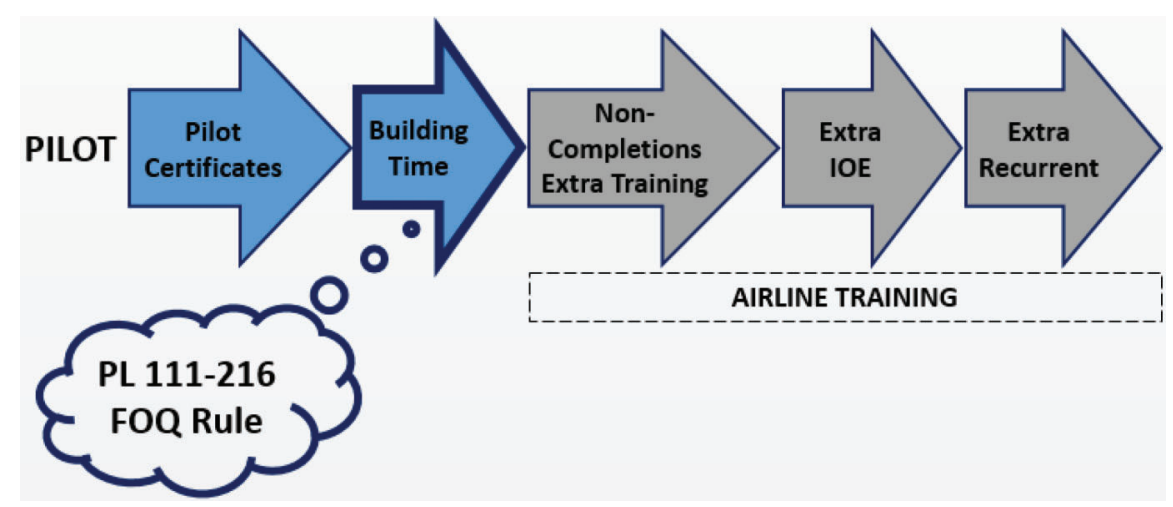

Figure 23. Timeline of pilot development from certificates to airline training.

1,500 total flight hours; and recently graduated from an AABI-Accredited Flight program or at least had a bachelor's degree, preferably an aviation degree.

The goal of the Airline Safety and Federal Aviation Administration Extension Act of 2010 (Public Law 111216) is to improve the safety of the American flying public. It is a complex law with many sections; the Pilot Source Study 2015 addresses only Section 216 "Flight Crewmember Screening and Qualifications" and Section 217 "Airline Transport Pilot Certification." By requiring Part 121 first officers to have an ATP and 1,500 total flight hours, the law essentially created a "Building Time" gap between earning a Commercial Pilot certificate and being hired by a Part 121 regional airline (see Figure 23).

Since existing data do not directly measure safety; it is inferred in this study that pilot performance is linked to safety. In the Pre-Law Pilot Source Studies 2010 and 2012, many pilots earned Commercial Pilot certificates and were hired by regional airlines with fewer than 1,500 total flight hours; these pilots out-performed their classmates in terms of completions and extra training events (Smith et al., 2010; Smith et al., 2013). The Post-Law Pilot Source Study 2015 in essence studied the effects of the gap that was extended by PL 111-216. The Pilot Source Study 2015 provides empirical evidence that the experience gap, which resulted from PL 111-216, was ineffectual in enhancing pilot performance and, by inference, the safety of the American flying public.

\section{Acknowledgement}

The analysis of the Pilot Source Study 2015 data was completed by the seven authors; additionally much of the work was accomplished by the behind-the-scenes supporters of the research. Research funding was provided by two universities, five major airlines, and two associations; the donors are listed in http://pilotsourcestudy.org/ (Town Hall Presentation). Most importantly, the research depended heavily on partnerships with the Regional Airline Association (RAA), Aviation Accreditation Board International (AABI), the 19 Part 121 U.S. regional airlines, and three Part 135 U.S. regional airlines represented in the study. To maintain objectivity, the Pilot Source Study 2015 fund did not request or accept any donations from RAA, AABI, or any regional airline. Data collection at the regional airlines was a major effort skillfully administered by Data Manager Jenna Ludwick, graduate student at Embry-Riddle Aeronautical University. Jenna was assisted at various airlines by Nancy Shane (Farmingdale State College-SUNY), Crystal Ferguson (EmbryRiddle Aeronautical University), Kiran Chilakalapudi (Arizona State University), and Nicolle Huang (Westminster College). Data consolidation was designed by the first three authors of this article and masterfully completed by Lisa Maddox (Ypsilon Associates). The authors were ably assisted with data analysis by Matthew Price and Allen Xie (Purdue University) and by Ryan Bearden (Middle Tennessee State University).

\section{References}

Air Line Pilots Association (ALPA). (2012, April 28). ALPA Comments to Notice of Proposed Rulemaking (NPRM) on Pilot Certification and Qualification Requirements for Air Carrier Operations, Docket No. FAA-2010-0100; Notice No. 12-01 [Press release]. Retrieved from http://www3.alpa.org

Air Line Pilots Association (ALPA). (2016, April). Airline pilots available to work for the right career opportunity. Airline Pilot, 85(3), 9-10.

Airline Safety and Federal Aviation Administration Extension Act of 2010. Public Law 111-216, 124 Stat, 2348. (2010).

Allied Pilots Association (APA). (2014, February 28). Allied Pilots Association on GAO pilot shortage report: "A broken business model, not a pilot shortage" [Press release]. Retrieved from https://www. alliedpilots.org/News/ID/1504

Aviation Accreditation Board International (AABI). (2016, February 26). Accreditation criteria manual (Form 201). Auburn, AL: Author. Retrieved from http://www.aabi.aero

Bjerke, E., Smith, G., Smith, M., Christensen, C., Carney, T., Craig, P., \& Niemczyk, M. (2016). Pilot source study 2015: US regional airline pilot hiring background characteristic changes consequent to Public Law 111-216 and the FAA first officer qualifications rule. Journal of Aviation Technology and Engineering, 5(2, 1). Retrieved from https:// doi.org/10.7771/2159-6670.1133

Boeing. (2015). 2015 pilot \& technician outlook. Retrieved from http:// www.boeing.com

Carey, B. (2015, June 25). Airline pilots: Low pay drives disputed pilot shortage. Retrieved from http://www.ainonline.com 
Church, S., Schlangenstein, M., \& Sasso, M. (2016, February 26). Republic Airways files for bankruptcy after pilot shortage. Retrieved from http://www.bloomberg.com

Creedy, K. (2016, February 4). Pilot training requires regulatory overhaul to improve safety: Part 1. Forbes Logistics and Transportation. Retrieved from http://www.forbes.com

Depperschmidt, C. L., Bliss, T. J., \& Casebolt, M. K. (2015). The effect of Public Law 111-216 on collegiate flight programs: Perceptions of aviation faculty and flight center personnel. Collegiate Aviation Review, 33(2), 53-65.

Envoy. (2016). Envoy pilot pipeline program. Retrieved from https:// www.envoyair.com

Families of Continental Flight 3407. (2016). Retrieved from http://www. 3407memorial.com

Federal Aviation Administration (FAA). (2010, February 8). New pilot certification requirements for air carrier operations (ANPRM, Docket No. FAA-2010-0100; Notice No. 10-02). Washington, DC: Department of Transportation.

Federal Aviation Administration (FAA). (2013, July 15). Pilot certification and qualification requirements for air carrier operations, Final rule (Docket No. FAA-2010-0100; Amdt. Nos. 61-130; 121-365; 135-127; 141; 142-149). Washington, DC: Department of Transportation.

Higgins, J., Bjerke, E., Lovelace, K., \& Leonard, A. (2016, May). Pilot supply forecast 2016. Presentation at the 2016 Regional Airline Association Annual Convention. Charlotte, NC.

International Civil Aviation Organization (ICAO). (2011). ICAO study reveals strong demand for qualified aviation personnel up to 2030. Retrieved from http://www.icao.int

McGee, M. (2015). Air transport pilot supply and demand: Current state and effects of recent legislation (Doctoral dissertation, Pardee RAND Graduate School, 2015). Retrieved from http://www.rand.org/content/ dam/rand/pubs/rgs_dissertations

National Transportation Safety Board. (2010). Aircraft accident report: Loss of control on approach Colgan Air, Inc. Operating as Continental Connection Flight 3407 Bombardier DHC-8-400, N200WQ Clarence Center, New York February 12, 2009 (NTSB/AAR-10/01). Washington, DC: National Transportation Safety Board.

Operating Requirements: Domestic, Flag, and Supplemental Operations, 14 C.F.R. § $121,2015$.
Regional Airline Association (RAA). (2015). Annual convention Retrieved from http://www.raa.org

Roddey, J. (2015, January 14). Airline industry leaders gather at EmbryRiddle to discuss pilot shortage. Retrieved from http://news.erau.edu

Schlangenstein, M. (2015, November 25). JetBlue shakes up pilot hiring by training them from scratch. Retrieved from http://www.bloomberg. $\mathrm{com} /$ news

Silk, R. (2016, January 4). Pilot shortage a growing problem in regional air service. Travel Weekly. Retrieved from http://www.travelweekly.com

Silk, R. (2016, January 19). Training rule blamed for pilot shortage. Travel Weekly. Retrieved from http://www.travelweekly.com

Silk, R. (2016, January 22). AA-owned regional carriers launch pilot training programs. Travel Weekly. Retrieved from http://www.travel weekly.com

Smith, G., Bjerke, E., Smith, M., Christensen, C., Carney, T., Craig, P., \& Niemczyk, M. (2016). Pilot source study 2015: An analysis of FAR Part 121 pilots hired after Public Law 111-216-Their backgrounds and subsequent successes in US regional airline training and operating experience. Journal of Aviation Technology and Engineering, 6(1), 64-89. https://doi.org/10.7771/2159-6670.1140

Smith, G. M., Bjerke, E., NewMyer, D. A., Niemczyk, M., \& Hamilton, R. A. (2010). Pilot source study: An analysis of pilot backgrounds and subsequent success in US regional airline training programs. International Journal of Applied Aviation Studies, 10(1), 73-96. Retrieved from https://www.academy.jccbi.gov/ama-800/Summer_2010.pdf

Smith, G. M., Herchko, D., Bjerke, E., Niemczyk, M., Nullmeyer, R., Paasch, J., \& NewMyer, D. A. (2013). The 2012 pilot source study (phase III): Response to the pilot certification and qualification requirements for air carrier operations. Journal of Aviation Technology and Engineering, 2(2), 13-23. https://doi.org/10.7771/2159-6670.1071

Templeton, P. (2016). Regional airlines are offering signing and retention bonuses to pilots. Retrieved from http://pilotjobs.atpflightschool.com/

The coming U.S. pilot shortage is real. (2015, February 16). Aviation Week. Retrieved from http://aviationweek.com/commercial-aviation/ coming-us-pilot-shortage-real

The truth about the profession. (2016). Retrieved from http:// thetruthabouttheprofession.weebly.com

United States Government Accountability Office (GAO). (2014, February). Aviation workforce: Current and future availability of airline pilots (GAO-14-232). Washington, DC: United States Government Accountability Office.

\section{Appendix-Summary of Results}

\begin{tabular}{|c|c|c|c|c|}
\hline PRE-LAW & & POST-LAW & & Significant Change \\
\hline \multicolumn{5}{|c|}{$\begin{array}{c}\text { Descriptive Statistics Differences-BACKGROUND Variables } \\
\text { Note: NS = Not Significant }\end{array}$} \\
\hline AABI Flight & $32 \%$ & AABI Flight & $23 \%$ & Decreased \\
\hline Aviation Degree & $66 \%$ & Aviation Degree & $51 \%$ & Decreased \\
\hline Military Pilot & $3 \%$ & Military Pilot & $12 \%$ & Increased \\
\hline CFI Certificate & $82 \%$ & CFI Certificate & $78 \%$ & Decreased \\
\hline Previous-Corporate Pilot & $15 \%$ & Previous-Corporate Pilot & $20 \%$ & Increased \\
\hline Previous-Flt Instructor & $53 \%$ & Previous-Flt Instructor & $46 \%$ & Decreased \\
\hline Dual Given & Mean 689 & Dual Given & Mean 940 & Increased \\
\hline Total Flight Hours & Mean 1597 & Total Flight Hours & Mean 3071 & Increased \\
\hline \multicolumn{5}{|c|}{ Descriptive Statistics Differences-OUTCOME Variables } \\
\hline Extra Training Events & Mean .52 & Extra Training Events & Mean 1.20 & Increased \\
\hline Completions & $93 \%$ & Completions & $84 \%$ & Decreased \\
\hline Normal IOE z-Score & $87 \%$ & Normal IOE z-Score & $88 \%$ & NS \\
\hline
\end{tabular}


Background Effects on Extra Training Between Pre-Law and Post-Law

Note: NS $=$ Not Significant

\begin{tabular}{|c|c|c|c|c|}
\hline Background Variable & Extra Training Events & Pre-Law Outcome & Post-Law Outcome & Effect \\
\hline & Zero & NS & Negative & $\begin{array}{l}\text { Associate Degree increased its negative effect } \\
\text { on zero extra training between Pre-Law and } \\
\text { Post-Law-yielding fewer Post-Law pilots } \\
\text { with zero extra training events. }\end{array}$ \\
\hline College Degree & One or More & NS & Negative & $\begin{array}{l}\text { No Degree increased its negative effect on } \\
\text { one or more extra training events between } \\
\text { Pre-Law and Post-Law-yielding more } \\
\text { Post-Law pilots with one or more extra } \\
\text { training events. }\end{array}$ \\
\hline Background Variable & Extra Training Events & Pre-Law Outcome & Post-Law Outcome & Effect \\
\hline
\end{tabular}

\section{Aviation Degree lost some of its positive} Zero Positive NS effect on zero extra training between PreLaw and Post-Law-yielding fewer PostLaw pilots with zero extra training events.

Aviation Degree

Aviation Degree increased its positive effect on one or more extra training events between

One or More NS Positive
Pre-Law and Post-Law-yielding fewer Post-Law pilots with one or more extra training events.

\begin{tabular}{lllll}
\hline Background Variable & Extra Training Events & Pre-Law Outcome & Post-Law Outcome & Effect \\
\hline
\end{tabular}

Zero Positive NS

AABI Flight Degree lost some of its positive effect on zero extra training between PreLaw and Post-Law-yielding fewer PostLaw pilots with zero extra training events.

AABI Flight Degree

One or More NS Positive

AABI Flight Degree increased its positive effect on one or more extra training events between Pre-Law and Post-Law-yielding fewer Post-Law pilots with one or more extra training events.

\begin{tabular}{|c|c|c|c|c|}
\hline Background Variable & Extra Training Events & Pre-Law Outcome & Post-Law Outcome & Effect \\
\hline \multirow{2}{*}{ Airline Experience } & Zero & Positive & More Positive & $\begin{array}{l}\text { Airline experience increased its positive } \\
\text { effect on zero Extra Training between Pre- } \\
\text { Law and Post-Law-yielding more Post- } \\
\text { Law pilots with zero extra training } \\
\text { events. }\end{array}$ \\
\hline & One or More & Positive & Less Positive & $\begin{array}{l}\text { Airline experience lost some of its positive } \\
\text { effect on one or more extra training events } \\
\text { between Pre-Law and Post-Law-yielding } \\
\text { more Post-Law pilots with one or more } \\
\text { extra training events. }\end{array}$ \\
\hline Background Variable & Extra Training Events & Pre-Law Outcome & Post-Law Outcome & Effect \\
\hline \multirow{2}{*}{ Corporate Experience } & Zero & Negative & NS & $\begin{array}{l}\text { Corporate experience decreased its } \\
\text { negative effect on zero Extra Training } \\
\text { between Pre-Law and Post-Law-yielding } \\
\text { more Post-Law pilots with zero extra } \\
\text { training events }\end{array}$ \\
\hline & One or More & NS & Negative & $\begin{array}{l}\text { Corporate experience increased its negative } \\
\text { effect on one or more extra training events } \\
\text { between Pre-Law and Post-Law-yielding } \\
\text { more Post-Law pilots with one or more extra } \\
\text { training events. }\end{array}$ \\
\hline
\end{tabular}


TABLE

(Continued)

Background Effects on Extra Training Between Pre-Law and Post-Law

Note: NS $=$ Not Significant

\begin{tabular}{ccccc}
\hline Background Variable & Extra Training Events & Pre-Law Outcome & Post-Law Outcome & Effect \\
\hline $\begin{array}{c}\text { Flight Instructor } \\
\text { Experience }\end{array}$ & Zero & NS & Negative & $\begin{array}{l}\text { Flight Instructor experience increased its } \\
\text { negative effect on zero Extra Training } \\
\text { between Pre-Law and Post-Law-yielding } \\
\text { fewer Post-Law pilots with zero extra } \\
\text { training events. }\end{array}$ \\
& One or More & Negative & Flight Instructor experience decreased its \\
negative effect on one or more extra training \\
events between Pre-Law and Post-Law- \\
yielding fewer Post-Law pilots with one or \\
more extra training events.
\end{tabular}

\begin{tabular}{|c|c|c|c|c|}
\hline Background Variable & Extra Training Events & Pre-Law Outcome & Post-Law Outcome & Effect \\
\hline \multirow[b]{2}{*}{ CFI Certificate } & Zero & Positive & NS & $\begin{array}{l}\text { CFI Certificate lost some of its positive effect } \\
\text { on zero Extra Training between Pre-Law and } \\
\text { Post-Law-yielding fewer Post-Law pilots } \\
\text { with zero extra training events. }\end{array}$ \\
\hline & One or More & NS & Positive & $\begin{array}{l}\text { CFI Certificate increased its positive effect on } \\
\text { one or more extra training events between } \\
\text { Pre-Law and Post-Law -yielding fewer } \\
\text { Post-Law pilots with one or more extra } \\
\text { training events. }\end{array}$ \\
\hline Background Variable & Extra Training Events & Pre-Law Outcome & Post-Law Outcome & Effect \\
\hline Dual Given & One or More & 693 hours & $\begin{array}{l}908 \text { hours } \\
1,025 \text { hours }\end{array}$ & $\begin{array}{l}\text { Dual Given lost some of its effect. More flight } \\
\text { instruction hours were less beneficial to } \\
\text { Regional Airline training for Post-Law } \\
\text { pilots. }\end{array}$ \\
\hline Background Variable & Extra Training Events & Pre-Law Outcome & Post-Law Outcome & Effect \\
\hline Total Flight Hours & One or More & 1,647 hours & 2,896 hours & $\begin{array}{l}\text { Total Flight Hours lost some of its effect. The } \\
\text { additional Total Flight Hours required by the } \\
\text { legislation is not beneficial to regional airline } \\
\text { training. As Total Flight Hours increased, } \\
\text { the number of extra training events also } \\
\text { increased - the result is a significant } \\
\text { positive correlation. }\end{array}$ \\
\hline
\end{tabular}

Background Effects on Completions Between Pre-Law and Post-Law

Note: NS = Not Significant

\begin{tabular}{|c|c|c|c|c|}
\hline Background Variable & Completion & Pre-Law Outcome & Post-Law Outcome & Effect \\
\hline \multirow{4}{*}{ College Degree } & No & NS & Positive & $\begin{array}{l}\text { Bachelor's Degree increased its positive } \\
\text { effect on non-completions between Pre-Law } \\
\text { and Post-Law-yielding fewer Post-Law } \\
\text { pilots with non-completions. }\end{array}$ \\
\hline & No & NS & Negative & $\begin{array}{l}\text { No Degree increased its negative effect on } \\
\text { non-completions between Pre-Law and Post- } \\
\text { Law-yielding more Post-Law pilots with } \\
\text { non-completions. }\end{array}$ \\
\hline & No & NS & Negative & $\begin{array}{l}\text { Associate Degree increased its negative effect } \\
\text { on non-completions between Pre-Law and } \\
\text { Post-Law-yielding more Post-Law pilots } \\
\text { with non-completions. }\end{array}$ \\
\hline & Yes & NS & Negative & $\begin{array}{l}\text { Associate Degree increased its negative effect } \\
\text { on completions between Pre-Law and Post- } \\
\text { Law-yielding fewer Post-Law pilots with } \\
\text { completions }\end{array}$ \\
\hline
\end{tabular}


TABLE

(Continued)

\begin{tabular}{|c|c|c|c|c|}
\hline \multicolumn{5}{|c|}{$\begin{array}{c}\text { Background Effects on Extra Training Between Pre-Law and Post-Law } \\
\text { Note: NS = Not Significant }\end{array}$} \\
\hline Background Variable & Completion & Pre-Law Outcome & Post-Law Outcome & \multirow{3}{*}{$\begin{array}{l}\text { Effect } \\
\text { Aviation Degree increased its positive effect } \\
\text { on non-completions between Pre-Law and } \\
\text { Post-Law-yielding fewer Post-Law pilots } \\
\text { with non-completions. } \\
\text { Aviation Degree lost its positive effect on } \\
\text { completions between Pre-Law and Post- } \\
\text { Law-yielding fewer Post-Law pilots with } \\
\text { completions. }\end{array}$} \\
\hline \multirow{2}{*}{ Aviation Degree } & No & NS & Positive & \\
\hline & Yes & Positive & Negative & \\
\hline Background Variable & Completion & Pre-Law Outcome & Post-Law Outcome & Effect \\
\hline \multirow{2}{*}{ AABI Flight Degree } & No & Positive & More Positive & \multirow{2}{*}{$\begin{array}{l}\text { AABI Flight Degree increased its positive } \\
\text { effect on non-completions between Pre-Lav } \\
\text { and Post-Law-yielding fewer Post-Law } \\
\text { pilots with non-completions. } \\
\text { AABI Flight Degree lost its positive effect or } \\
\text { completions between Pre-Law and Post- } \\
\text { Law-yielding fewer Post-Law pilots with } \\
\text { completions. }\end{array}$} \\
\hline & Yes & Positive & Negative & \\
\hline Background Variable & Completion & Pre-Law Outcome & Post-Law Outcome & Effect \\
\hline \multirow[t]{2}{*}{ Airline Experience } & No & NS & Negative & \multirow{2}{*}{$\begin{array}{l}\text { Airline experience increased its negative } \\
\text { effect on non-completions between Pre-Law } \\
\text { and Post-Law-yielding more Post-Law } \\
\text { pilots with non-completions. } \\
\text {---- }\end{array}$} \\
\hline & Yes & NS & NS & \\
\hline Background Variable & Completion & Pre-Law Outcome & Post-Law Outcome & Effect \\
\hline \multirow{2}{*}{ Corporate Experience } & No & NS & Negative & \multirow{2}{*}{$\begin{array}{l}\text { Corporate experience increased its negative } \\
\text { effect on non-completions between Pre-Law } \\
\text { and Post-Law-yielding more Post-Law } \\
\text { pilots with non-completions. } \\
\text { Previous Corporate experience increased its } \\
\text { positive effect on completions between Pre- } \\
\text { Law and Post-Law-yielding more Post- } \\
\text { Law pilots with completions. }\end{array}$} \\
\hline & Yes & Negative & Positive & \\
\hline Background Variable & Completion & Pre-Law Outcome & Post-Law Outcome & Effect \\
\hline \multirow{3}{*}{$\begin{array}{l}\text { Flight Instructor } \\
\text { Experience }\end{array}$} & No & NS & Positive & \multirow{3}{*}{$\begin{array}{l}\text { Flight Instructor experience increased its } \\
\text { positive effect on non-completions between } \\
\text { Pre-Law and Post-Law-yielding fewer } \\
\text { Post-Law pilots with non-completions. } \\
\text { Flight Instructor experience lost its positive } \\
\text { effect on completions between Pre-Law and } \\
\text { Post-Law-yielding fewer Post-Law pilots } \\
\text { with completions. }\end{array}$} \\
\hline & & & & \\
\hline & Yes & Positive & Negative & \\
\hline
\end{tabular}

Background Effects on Completions Between Pre-Law and Post-Law

Note: NS $=$ Not Significant

\begin{tabular}{ccccc}
\hline Background Variable & Completion & Pre-Law Outcome & Post-Law Outcome & Effect \\
\hline No & NS & Positive & $\begin{array}{r}\text { CFI Certificate increased its positive effect on } \\
\text { non-completions between Pre-Law and Post- } \\
\text { Law-yielding fewer Post-Law pilots with } \\
\text { non-completions. } \\
\text { CFI Certificate decreased its positive effect } \\
\text { on completions between Pre-Law and Post- } \\
\text { Law-yielding fewer Post-Law pilots with } \\
\text { completions. }\end{array}$ \\
\hline
\end{tabular}


TABLE

(Continued)

\section{Background Effects on Extra Training Between Pre-Law and Post-Law}

Note: NS $=$ Not Significant

\begin{tabular}{ccccc}
\hline Background Variable & Completion & Pre-Law Outcome & Post-Law Outcome & Effect \\
\hline Dual Given & No & 821 hours & 1,125 hours & $\begin{array}{c}\text { Dual Given lost some of its effect. More flight } \\
\text { instruction hours were less beneficial to } \\
\text { regional airline training for Post-Law pilots; } \\
\text { in fact, the completers have fewer dual-given } \\
\text { hours than non-completers. }\end{array}$ \\
\hline Background Variable & Completion & Pre-Law Outcome & Post-Law Outcome & Effect \\
\hline To & 2,102 hours & 3,996 hours & $\begin{array}{l}\text { Total Flight Hours lost some of its effect. The } \\
\text { additional Total Flight Hours required by the } \\
\text { legislation is less beneficial to regional } \\
\text { airline training for Post-Law pilots. As the } \\
\text { number of Total Flight Hours increases, so } \\
\text { do the proportion of non-completions-the } \\
\text { result is a significant positive correlation. }\end{array}$ \\
\hline
\end{tabular}

Background Effects on IOE Between Pre-Law and Post-Law

Note: NS $=$ Not Significant

\begin{tabular}{ccccc}
\hline Background Variable & IOE & Pre-Law Outcome & Post-Law Outcome & Effect \\
\hline AABI Flight Degree & Normal & Positive & NS & $\begin{array}{r}\text { AABI Flight Degree lost some of its positive } \\
\text { effect on Normal IOE between Pre-Law and } \\
\text { Post-Law-yielding fewer Post-Law pilots } \\
\text { with Normal IOE. } \\
\text { AABI Flight Degree increased its positive } \\
\text { effect on Extra IOE between Pre-Law and } \\
\text { Post-Law-yielding fewer Post-Law pilots } \\
\text { with Extra IOE. }\end{array}$ \\
\hline
\end{tabular}

MaryJo Smith is the senior research scientist and CEO of Ypsilon Associates-independent consultants specializing in qualitative and quantitative research and statistical analysis. She earned her $\mathrm{PhD}$ in educational psychology with an emphasis in evaluation, statistics, and research from the University of Minnesota in 1999. In her role as an evaluation consultant, she is the ATQP data manager for two airline consortiums in Europe.

Guy Smith is a professor emeritus at Embry-Riddle Aeronautical University. He is a 21-year US Navy veteran where most of his career was on aircraft carriers flying the S-3A Viking. He earned a doctorate in adult and higher education from Montana State University in 1994 and is best known for his research in facilitation teaching methods for adult learners and airline pilot training.

Elizabeth Bjerke currently serves as the associate dean of the John. D. Odegard School of Aerospace Sciences at the University of North Dakota in Grand Forks, ND. After receiving her PhD in educational leadership, her research efforts have focused on student success in collegiate aviation programs, aviation assessment, and accreditation practices, as well as being a researcher on the 2010 and 2012 Pilot Source Studies.

Cody Christensen received a doctorate in adult and higher education in 2013 from the University of South Dakota. He is an assistant professor and program coordinator of the aviation program at South Dakota State University in Brookings, SD. His current research involves student safety, financial literacy, and agricultural aviation. He holds an Airline Transport Pilot certificate and was an airline captain for a regional airline before transitioning into academia.

Thomas Carney is a professor of aviation technology at Purdue University in West Lafayette, IN. He holds an Airline Transport Pilot certificate with over 49 years of experience as a pilot. He holds MS and $\mathrm{PhD}$ degrees in atmospheric science. His primary research areas of interest include aviation meteorology, synoptic-scale dynamics and energetics, the use of aircraft for airborne research applications, and pilots' use of weather technology in the cockpit.

Paul Craig earned a doctor of education degree in 1998 and is a professor of aerospace at Middle Tennessee State University in Murfreesboro, TN. He has been the Principal Investigator on four NASA research grants including work with computerized flight decks, scenario-based training, team dynamics, and decision-making. He holds the Airline Transport Pilot certificate and is a Gold Seal Flight Instructor.

Mary Niemczyk is an associate professor and chair of the aviation graduate programs at the Polytechnic School of Arizona State University in Mesa, AZ. She has earned academic degrees in accounting, a MBAAviation, and a $\mathrm{PhD}$ in learning and instructional technology. Her research interests center on improving instructional and learning strategies to enhance the performance of individuals in complex, ill-defined environments, such as aviation. 